\title{
Tropospheric products of the second GOP European GNSS reprocessing (1996-2014)
}

\author{
Jan Dousa, Pavel Vaclavovic, and Michal Elias \\ NTIS - New Technologies for the Information Society, Geodetic Observatory Pecný, RIGTC, 25066 Zdiby, Czech Republic \\ Correspondence to: Jan Dousa (jan.dousa@ pecny.cz)
}

Received: 15 January 2017 - Discussion started: 2 February 2017

Revised: 14 August 2017 - Accepted: 28 August 2017 - Published: 29 September 2017

\begin{abstract}
In this paper, we present results of the second reprocessing of all data from 1996 to 2014 from all stations in International Association of Geodesy (IAG) Reference Frame Sub-Commission for Europe (EUREF) Permanent Network (EPN) as performed at the Geodetic Observatory Pecný (GOP). While the original goal of this research was to ultimately contribute to the realization of a new European Terrestrial Reference System (ETRS), we also aim to provide a new set of GNSS (Global Navigation Satellite System) tropospheric parameter time series with possible applications to climate research. To achieve these goals, we improved a strategy to guarantee the continuity of these tropospheric parameters and we prepared several variants of troposphere modelling. We then assessed all solutions in terms of the repeatability of coordinates as an internal evaluation of applied models and strategies and in terms of zenith tropospheric delays (ZTDs) and horizontal gradients with those of the ERA-Interim numerical weather model (NWM) reanalysis. When compared to the GOP Repro1 (first EUREF reprocessing) solution, the results of the GOP Repro2 (second EUREF reprocessing) yielded improvements of approximately 50 and $25 \%$ in the repeatability of the horizontal and vertical components, respectively, and of approximately $9 \%$ in tropospheric parameters. Vertical repeatability was reduced from 4.14 to $3.73 \mathrm{~mm}$ when using the VMF1 mapping function, a priori ZHD (zenith hydrostatic delay), and non-tidal atmospheric loading corrections from actual weather data. Raising the elevation cut-off angle from 3 to $7^{\circ}$ and then to $10^{\circ}$ increased RMS from coordinates' repeatability, which was then confirmed by independently comparing GNSS tropospheric parameters with the NWM reanalysis. The assessment of tropospheric horizontal gradients with respect to the ERA-Interim revealed a strong sensitivity of estimated gra-
\end{abstract}

dients to the quality of GNSS antenna tracking performance. This impact was demonstrated at the Mallorca station, where gradients systematically grew up to $5 \mathrm{~mm}$ during the period between 2003 and 2008, before this behaviour disappeared when the antenna at the station was changed. The impact of processing variants on long-term ZTD trend estimates was assessed at 172 EUREF stations with time series longer than 10 years. The most significant site-specific impact was due to the non-tidal atmospheric loading followed by the impact of changing the elevation cut-off angle from 3 to $10^{\circ}$. The other processing strategy had a very small or negligible impact on estimated trends.

\section{Introduction}

The US Global Positioning System (GPS) became operational in 1995 as the first Global Navigation Satellite System (GNSS). Since that time, this technology has been transformed into a fundamental technique for positioning and navigation in everyday life. Hundreds of GPS permanent stations have been deployed for scientific purposes throughout Europe and the world, and the first stations have collected GPS data for approximately the last two decades. In 1994, a science-driven global network of continuously operating GPS stations was established by the International GNSS Service, IGS (Dow et al.m 2009), of the International Association of Geodesy (IAG) to support the determination of precise GPS/GNSS orbits, and clock and earth rotation parameters, which are necessary for obtaining high-accuracy GNSS analyses for scientific applications. A similar network, but regional in its scope, was also organized by the IAG Reference Frame Sub-Commission for Europe (EUREF) in 1996, 
which was called the EUREF Permanent Network (EPN; Bruyninx et al., 2012). Although its primary purpose was to maintain the European Terrestrial Reference System (ETRS), the EPN also attempted to develop a pan-European infrastructure for scientific projects and co-operations (Ihde et al., 2014). Since 1996, the EPN has grown to include approximately 300 operating stations, which are regularly distributed throughout Europe and its surrounding areas. Today, EPN data are routinely analysed by 18 EUREF analysis centres.

Throughout the past two decades, GPS data analyses of both global and regional networks have been affected by various changes in processing strategy and updates of precise models and products, reference frames and software packages. To reduce discontinuities in products, particularly within coordinate time series, homogeneous reprocessing was initiated by the IGS and EUREF on a global and regional scale, respectively. To exploit the improvements in these IGS global products, the second European reprocessing was performed in 2015-2016, with the ultimate goal of providing a newly realized ETRS.

Currently, station coordinate parameter time series from reprocessed solutions are mainly used in the solid earth sciences as well as to maintain global and regional terrestrial reference systems. Additionally, from an analytical perspective, the long-term series of estimated parameters and their residuals are useful for assessing the performances of applied models and strategies over a given period. Moreover, tropospheric parameters derived from this GNSS reanalysis could be useful for climate research (Yuan et al., 1993), due to their high temporal resolution and unrivalled relative accuracy for sensing water vapour when compared to other techniques, such as radio sounding, water vapour radiometers and radio occultation (Ning, 2012). In this context, the GNSS zenith tropospheric delay (ZTD) represents a site-specific parameter characterizing the total signal path delay in the zenith due to both dry (hydrostatic) and wet contributions of the neutral atmosphere, the latter of which is known to be proportional to precipitable water (Bevis et al., 1994).

With the second EUREF reprocessing, the secondary goal of the Geodetic Observatory Pecný (GOP) was to support the activity of Working Group 3 of the COST Action ES1206 (Guerova et al., 2016), which addresses the evaluation of existing and future GNSS tropospheric products and assesses their potential uses in climate research. For this purpose, the GOP provided several solution variants, with a special focus on optimal tropospheric estimates, including VMF1 vs. GMF mapping functions, the use of different elevation cut-off angles and estimates of tropospheric horizontal gradients using different time resolutions. Additionally, in order to enhance tropospheric outputs, we improved the processing strategy in a variety of ways compared to the GOP Repro1 (first EUREF reprocessing) solutions (Douša and Václavovic, 2012): (1) by combining tropospheric parameters during midnights and across GPS week breaks, (2) by checking weekly coordinates before their substitutions in order to estimate tro- pospheric parameters and (3) by filtering out problematic stations by checking the consistency of daily coordinates. The results of this GOP reprocessing, including all available variants, were assessed using internal evaluations of applied models and strategy settings and using external validations with independent tropospheric parameters derived from numerical weather model (NWM) reanalyses.

The processing strategy used in the second GOP reanalysis of the EUREF Permanent Network is described in Sect. 2, and the new approach that is developed to guarantee a continuity of estimated tropospheric parameters during midnights as well as between different GPS weeks is summarized in Sect. 3. The relationship between mean tropospheric horizontal gradients and the quality of low-elevation GNSS tracking is explained in Sect. 4. The results of internal and external evaluations of GOP solution variants and processing models are presented in Sect. 4, and the assessment of impacts of specific variants on estimated ZTD trends are is presented in Sect. 5. The last section concludes our findings and suggests avenues of future research.

\section{GOP processing strategy and solution variants}

The EUREF GOP analysis centre was established in 1997 and contributed to operational EUREF analyses until 2013 by providing final, rapid and near-real-time solutions. Recently, the GOP changed its contributions to that of a long-term homogeneous reprocessing of all data from the EPN historical archive. The GOP solution of the first EUREF reanalysis (Völksen, 2011) comprised the processing of a subnetwork of 70 EPN stations during the period of 1996-2008. In 2011, for the first time, the GOP reprocessed the entire EPN network (spanning a period of 1996-2010) in order to validate the European reference frame and to provide the first homogeneous time series of tropospheric parameters for all EPN stations (Douša and Václavovic, 2012).

In the second EUREF reprocessing (Repro2), the GOP analysed data obtained from the entire EPN network from a period of 1996-2014 using the Bernese GNSS Software version 5.2 (Dach et al., 2015). The GOP strategy relies on a network approach utilizing double-difference observations. Only GPS data from the EPN stations were included according to official validity intervals provided by the EPN Central Bureau (http://epncb.oma.be). Two products were derived from the reprocessing campaign in order to contribute to a combination at the EUREF level performed by the coordinator of analysis centres and the coordinator of troposphere products: (1) site coordinates and corresponding variancecovariance information in daily and weekly SINEX files and (2) site tropospheric parameters in daily Solution (Software/technique) INdependent EXchange Format for combination of TROpospheric estimates (SINEX_TRO) files.

This GOP processing was clustered into eight subnetworks (Fig. 1) and then stacked into daily network solutions 
Table 1. Characteristics of GOP reprocessing models.

\begin{tabular}{|c|c|}
\hline Processing options & Description \\
\hline Products & CODE precise orbit and earth rotation parameters from the second reprocessing. \\
\hline Observations & $\begin{array}{l}\text { Dual-frequency code and phase GPS observations from L1 and L2 carriers. Elevation cut-off angle } 3^{\circ} \text {, } \\
\text { elevation-dependent weighting } 1 / \cos ^{2} \text { (zenith), double-difference observations and observations with } 3 \text { min } \\
\text { sampling rate. }\end{array}$ \\
\hline Reference frame & $\begin{array}{l}\text { IGb08 realization - core stations set as fiducial after a consistency checking. Coordinates estimated using a } \\
\text { minimum constraint. }\end{array}$ \\
\hline Antenna model & GOP: IGS08_1832 model (receiver and satellite phase centre offsets and variations). \\
\hline Troposphere & $\begin{array}{l}\text { A priori zenith hydrostatic delay/mapping function: GPT/GMFh (GO0) and VMF1/VMF1h (GO1-GO6). Esti- } \\
\text { mated ZWD corrections every hour using the VMF1 wet mapping function - } 5 \text { and } 1 \mathrm{~m} \text { for absolute and relative } \\
\text { constraints, respectively. Estimated horizontal NS and EW tropospheric gradients every } 6 \mathrm{~h} \text { (GO0-GO5) or } 24 \mathrm{~h} \\
\text { (GO6) without a priori tropospheric gradients and constraints. }\end{array}$ \\
\hline Ionosphere & $\begin{array}{l}\text { Eliminated using the ionosphere-free linear combination (GO0-GO6). Applying higher-order effects estimated } \\
\text { using the CODE global ionosphere product (GO5). }\end{array}$ \\
\hline Loading effects & $\begin{array}{l}\text { Atmospheric tidal loading and hydrology loading not applied. Ocean tidal loading FES2004 used. Non-tidal } \\
\text { atmospheric loading introduced in advanced variants from the model from TU Vienna (GO4-GO6). }\end{array}$ \\
\hline
\end{tabular}

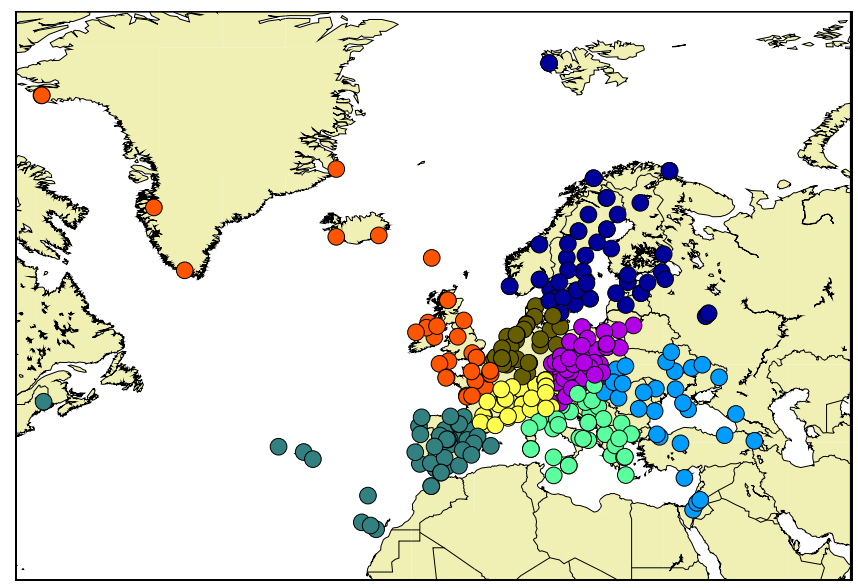

Figure 1. EUREF Permanent Network's clusters (designated by different colours) in the second GOP reprocessing.

with pre-eliminated integer phase ambiguities when ensuring strong ties to the IGS08 reference frame. This strategy introduced state-of-the-art models (IERS Conventions, 2010) that are recommended as standards for highly accurate GNSS analyses, particularly for the maintenance of the reference frame. Additionally, the use of precise orbits obtained from the second CODE (Centre of Orbit Determination in Europe) global reprocessing (Dach et al., 2014) guaranteed complete consistency between all models on both the provider and user sides. Characteristics of this GOP data reprocessing strategy and their models are summarized in Table 1. Additionally, seven processing variants were performed during the GOP Repro2 analysis for studying selected models or settings: (a) applying the tropospheric mapping function model GMF (Böhm et al., 2006a) vs. VMF1 (Böhm et al., 2006b), with the latter based on actual weather information; (b) increasing the temporal resolution of tropospheric linear horizontal gradients in the north and east directions; (c) using three different elevation cut-off angles, namely 3,7 and $10^{\circ}$; (d) modelling atmospheric loading effects; and (e) modelling higherorder ionospheric effects. Table 2 summarizes the settings and models of solution variants selected for generating coordinate and troposphere products, which are supplemented with variant rationales.

Within the processing, we screened station coordinate repeatabilities from weekly combined solutions and we identified any problematic station for which the north/east/up residuals exceeded 15/15/30 $\mathrm{mm}$ or RMS of the north/east/up coordinate component exceeded values $10 / 10 / 20 \mathrm{~mm}$. Such station was a priori excluded from the tropospheric product for the corresponding day. There were other standard control procedures within the processing when the individual station could have been excluded, e.g. if (a) less than $60 \%$ of GNSS data were available, (b) code or phase data revealed poor quality, (c) station metadata were found inconsistent with data file header information (receiver, antenna and dome names, antenna eccentricities), and (d) phase residuals were too large for all satellites in the processing period, indicating a problem with the station. Tropospheric parameters were estimated practically without constraints (a priori $\sigma$ greater than $1 \mathrm{~m}$ ); thus, parameter formal errors reflect the relative uncertainties of estimates. Usually, large errors indicate the lack of observations contributing to the parameter. During the tropospheric parameter evaluations, we applied the filter for exceeding formal errors of estimated parameters (ZTD $\sigma$ greater than $3 \mathrm{~mm}$, normal cases stay below $1 \mathrm{~mm}$ ).

\section{Ensuring ZTD continuity during midnights}

When site tropospheric parameter time series generated from the second EUREF reprocessing are applied to climate research, they should be free of artificial offsets in order 
Table 2. GOP solution variants for the assessment of selected models and settings.

\begin{tabular}{lll}
\hline Solution ID & Specific settings and differences & Remarks and rationales \\
\hline GO0 & GMF and $3^{\circ}$ cut-off & Legacy solution for Repro1 \\
GO1 & VMF1 and $3^{\circ}$ cut-off & New candidate for Repro2 \\
GO2 & Same as GO1; $7^{\circ}$ cut-off & Impact of elevation cut-off angle \\
GO3 & Same as GO1; $10^{\circ}$ cut-off & Impact of elevation cut-off angle \\
GO4 & Same as GO1; atmospheric loading & Non-tidal atmospheric loading applied \\
GO5 & Same as GO4; higher-order ionosphere & Higher-order ionosphere effect not applied \\
GO6 & Same as GO4; 24 hradients & Stacking tropospheric gradients to 24 h sampling \\
\hline
\end{tabular}

to avoid misinterpretations (Bock et al., 2014). However, GNSS processing is commonly performed on a daily basis according to adopted standards for data and product dissemination. Thus far, EUREF analysis centres have provided independent daily solutions, although precise IGS products are combined and distributed on a weekly basis. Station coordinates are estimated on a daily basis and are later combined to form more stable weekly solutions. According to the EUREF analysis centre guidelines (http://www.epncb.oma.be/_documentation/guidelines/ guidelines_analysis_centres.pdf), weekly coordinates should be used to estimate tropospheric parameters on a daily basis, but there are no requirements with which to guarantee the continuity of tropospheric parameters during midnights. Additionally, there are also discontinuities on a weekly basis, as neither daily coordinates nor hourly tropospheric parameters are combined across midnights between corresponding adjacent GPS weeks.

The impact of a 3-day combination was previously studied when assessing the tropospheric parameters stemming from the second IGS reprocessing campaign 2016 in the GOPTropDB database (Győri and Douša, 2016). We compared two global tropospheric products provided by the analysis centre CODE differing only in the procedure of combining tropospheric parameters from the daily original solutions. The first product, COF, was based purely on a single-day solution while the second product, COD, was based on a 3-day combination (Dach et al., 2014). Sub-daily statistics were calculated by comparing $2 \mathrm{~h}$ ZTD estimates from both products during 2013. There were no significant biases observed, but mean standard deviation estimated from differences reached $0.8 \mathrm{~mm}$ in ZTD over a day and almost $1.8 \mathrm{~mm}$ close to the day boundaries. Similarly, a dispersion characterized by $1 \sigma$ over all stations reached $0.5 \mathrm{~mm}$ for the former but up to $1.2 \mathrm{~mm}$ for the latter. Actual differences in ZTDs could even be larger, because this case used approximations leading to smooth low-resolution values close to the day boundaries.

During the first GOP reprocessing, there was no way to guarantee tropospheric parameter continuity at midnight, as the troposphere was modelled by applying a piecewise constant model. In these cases, tropospheric parameters with a temporal resolution of $1 \mathrm{~h}$ were reported in the middle of the hour, as was originally estimated. In the second GOP reprocessing, using again hourly estimates, we applied a piecewise linear model for the tropospheric parameters. The parameter continuities during midnights were not guaranteed implicitly, but only by an explicit combination of parameters at daily boundaries. For the combination procedure we used 3 consecutive days while the tropospheric product stems from the middle day. The procedure is done again for 3 consecutive days shifted by 1 day. A similar procedure, using the piecewise constant model, was applied for estimating weekly coordinates which aimed to minimize remaining effects in consistency at the breaks of GPS weeks (on Saturday at midnight). The coordinates of the weekly solution corresponding to the middle day of a 3-day combination were fixed for the tropospheric parameter estimates. In the last step, we transformed the piecewise linear model to the piecewise constant model expressed in the middle of each hourly interval (HR:30), which was saved in the SINEX_TRO format to support the EUREF combination procedure requiring such sampling. The original piecewise linear parameter model was thus lost, and, to retain this information in the official product in the SINEX_TRO format, we additionally stored values for full hours (HR:00). Figure 2 summarizes four plots displaying tropospheric solutions with discontinuities in the left panels $(a, c)$ and enforcing tropospheric continuities in the right panels $(b, d)$. While the upper plots $(a, b)$ display the piecewise constant model, bottom plots (c, d) indicate the solution representing the piecewise linear model. The GOP Repro1 implementation is thus represented by the Fig. 2a plot while the GOP Repro2 solution corresponds to Fig. 2d and, alternatively, Fig. $2 b$.

These theoretical concepts were practically tested using a limited dataset in 1996 (Fig. 3). The panels in Fig. 3 follow the organization of the theoretical plots shown in Fig. 2; corresponding formal errors are also plotted along with estimated ZTDs. Discontinuities are visible in the left-hand plots and are usually accompanied by increasing formal errors for parameters close to data interval boundaries. As expected, discontinuities disappear in the right-hand plots. Although the values between 23:30 and 00:30 on 2 adjacent days are not connected by a line in the top-right plot, continuity was enforced for midnight parameters anyway, as seen 


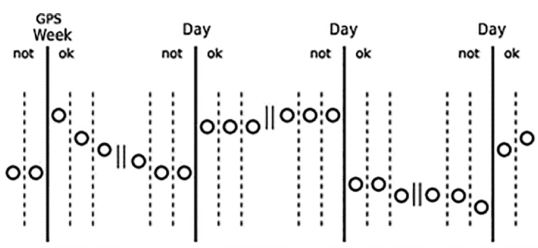

(a)

Time $\cdot>$

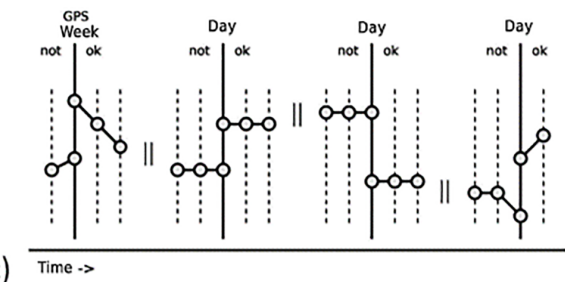

(b)

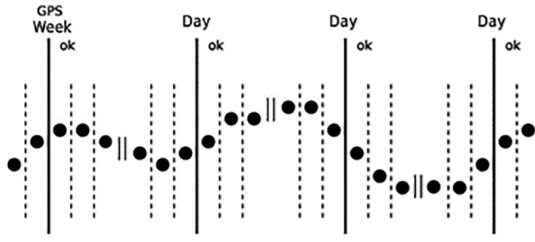

(b) Time $\cdot>$

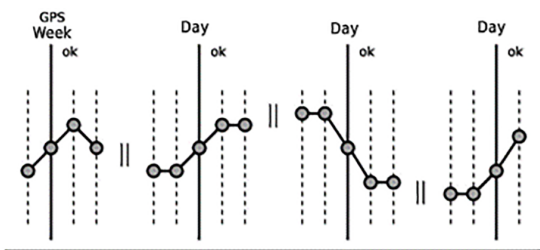

(d)

(d) Time $>$

Figure 2. Charts of four variants of representation of tropospheric parameters in time ( $x$ axis, with no specific dates). Right (b, d) and left (a, c) panels display estimates made with and without midnight combinations, respectively. Top (a, b) and bottom (c, d) panels display the piecewise constant and the linear model, respectively. Ok vs. not ok indicates a consistency vs. inconsistency, respectively, at daily or GPS week boundaries, the latter representing a specific case of the former.

in the bottom-right plot. Formal errors also became smooth near day boundaries, thus characterizing the contribution of data from both days and demonstrating that the concept behaves as expected in its practical implementation.

\section{Quality of the observations and impact on tropospheric gradients}

Recently, we have developed a new interactive web interface to conduct tropospheric parameter comparisons in the GOP-TropDB (Győri and Douša, 2016), which is being prepared for the IGS Tropospheric Working Group web (http: //twg.igs.org/; Dousa et al., 2017). Using the interface, we observed large systematic tropospheric gradients during specific years at several EPN stations. Generally, from GNSS data, we can only estimate total tropospheric horizontal gradients without being able to distinguish between dry and wet contributions. The former is mostly due to horizontal asymmetry in atmospheric pressure, and the latter is due to asymmetry in the water vapour content. The latter is thus more variable in time and space than the former (Li et al., 2015). Regardless, mean gradients should be close to zero, whereas dry gradients may tend to point slightly more to the equator, corresponding to latitudinal changes in atmosphere thickness (Meindl et al., 2004). Similarly, orography-triggered horizontal gradients can appear due to the presence of high mountain ranges in the vicinity of the station (Morel et al., 2015). Such systematic effects can reach the maximum submillimetre level, while a higher long-term gradient (i.e. that above $1 \mathrm{~mm}$ ) is likely more indicative of issues with site instrumentation, the environment or modelling effects. Therefore, in order to clearly identify these systematic effects, we also compared our gradients with those calculated from the ERA-Interim.

It is beyond the scope of this paper to investigate in detail the correlation between tropospheric horizontal gradients and effects such as antenna tracking performance. However, we do observe a strong impact in the most extreme case identified when comparing gradients from the GNSS and the ERA-Interim for all EPN stations. Figure 4 shows the monthly means of differences in the north and east tropospheric gradients from the MALL station (Mallorca, Spain). These differences increase from $0 \mathrm{~mm}$ up to $-4 \mathrm{~mm}$ and $2 \mathrm{~mm}$ for the east and north gradients, respectively, within the period of June 2003-October 2008. Such large monthly differences in GNSS and NWM gradients are not realistic and were attributed to data processing when long-term increasing biases dropped down to zero on 1 November 2008 , immediately after the antenna and receiver were changed at the station. During the same period, yearly mean ZTD differences in the ERA-Interim steadily changed from about $3 \mathrm{~mm}$ to about $-12 \mathrm{~mm}$ and immediately dropped down to $-2 \mathrm{~mm}$ in 2008 after the antenna change.

The EPN Central Bureau (http://epncb.oma.be), operating at the Royal Observatory of Belgium (ROB), provides a web service for monitoring GNSS data quality and includes monthly snapshots of the tracking characteristics of all stations. The sequence of plots displayed in Fig. 5, representing the interval of interest (2002, 2004, 2006 and 2008), reveals a slow but systematic and horizontally asymmetric degradation of the capability of the antenna to track low-elevation observations at the station. Therefore, we analysed days of the year (DoY) 302 and 306 (corresponding to 28 October and 1 November 2008) with the in-house G-Nut/Anubis software (Václavovic and Douša, 2016) and observed differences in the sky plots of these 2 days. The left-hand plot in Fig. 6 
(a)

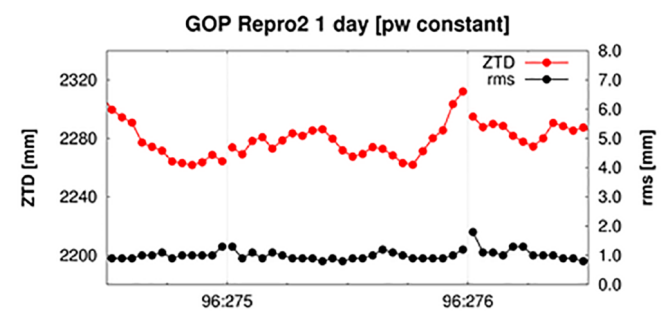

(c)

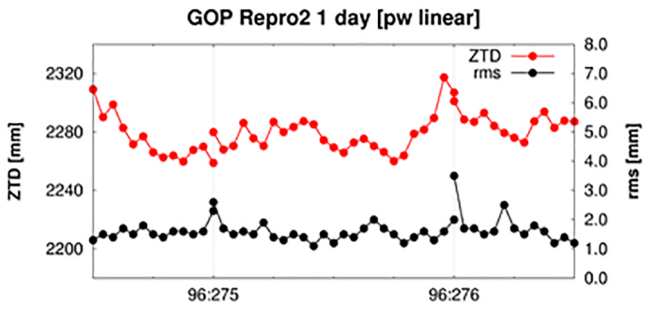

(b)

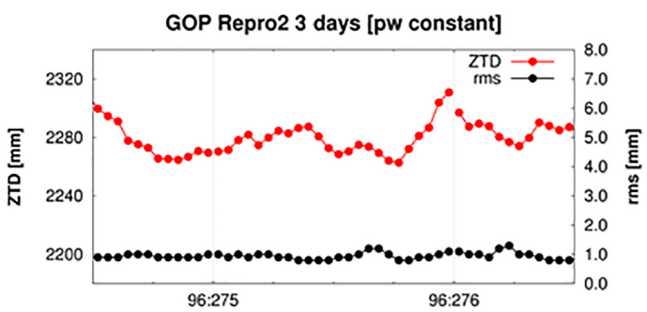

(d)

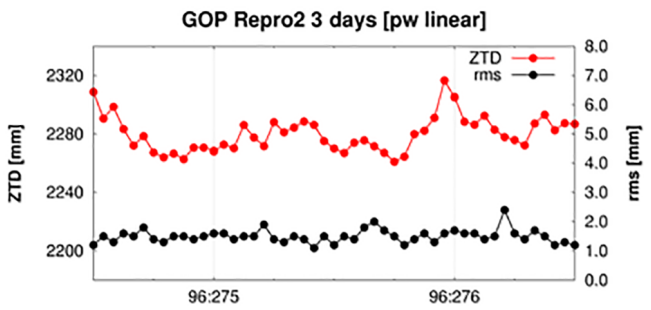

Figure 3. Four variants of representation of tropospheric parameters. Right $(\mathbf{b}, \mathbf{d})$ and left $(\mathbf{a}, \mathbf{c})$ panels display estimates with and without midnight combinations, respectively. Top (a, b) and bottom (c, d) panels display the piecewise constant and the piecewise linear model, respectively.

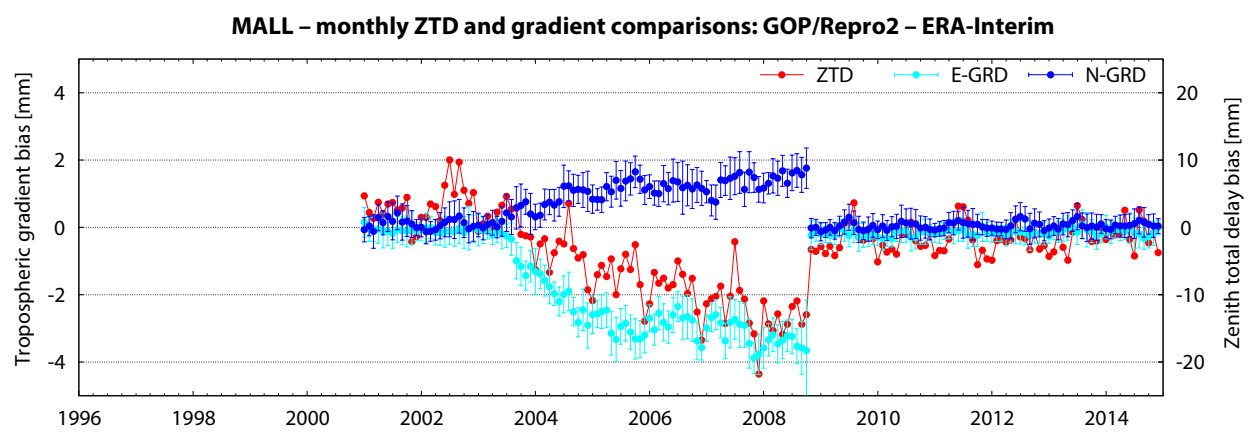

Figure 4. MALL station - monthly mean differences in tropospheric horizontal gradients with respect to the ERA-Interim.

depicts the severe loss of dual-frequency observations up to a $25^{\circ}$ elevation cut-off angle in the southeast direction (with an azimuth of $90-180^{\circ}$ ), which causes the tropospheric linear gradient of approximately $5 \mathrm{~mm}$ to point in the opposite direction. Figure 10 also demonstrates that an increasing loss of second frequency observations appears to occur in the east (represented as black dots). The right-hand plot in this figure demonstrates that both of these effects fully disappeared after the antenna was replaced on 30 October 2008 (DoY 304), resulting in the appearance of normal sky plot characteristics and a GLONASS constellation with one satellite providing only single-frequency observations (represented as black lines).

This situation demonstrates the high sensitivity of the estimated gradients on data asymmetry, particularly at lowelevation angles. The systematic behaviour of these monthly mean gradients, their variations from independent data and a profound progress over time seem to be useful indicators of instrumentation-related issues at permanent GNSS stations.
It is also considered that gradient parameters can be a valuable method as a part of ZTD data screening procedure (Bock et al., 2016).

Although the station MALL represented an extreme case, biases at other stations were observed too, e.g. GOPE (19962002), TRAB (1999-2008), CREU (2000-2002), HERS (1999-2001), GAIA (2008-2014) and others. Site-specific, spatially or temporally correlated biases suggest different possible reasons such as site-instrumentation effects including the tracking quality and phase centre variation (PCV) models, site-environment effects including multipath and seasonal variation (e.g. winter snow-ice coverage), edgenetwork effects when processing double-difference observations, spatially correlated effects in reference frame realization and possibly others. The problematic stations and periods mentioned above were however still included in comparisons and trend analysis because of the lack of objective criteria for their identification, which should be studied in future. 



Figure 5. Low-elevation tracking problems at the MALL station during the period of 2003-2008. From top-left to bottom-right: January 2002, 2004, 2006 and 2008 (courtesy of the EPN Central Bureau, ROB).

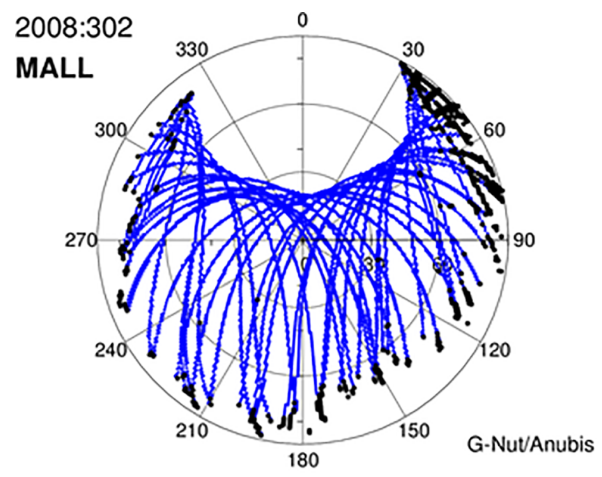

(a) GPS • GLO •

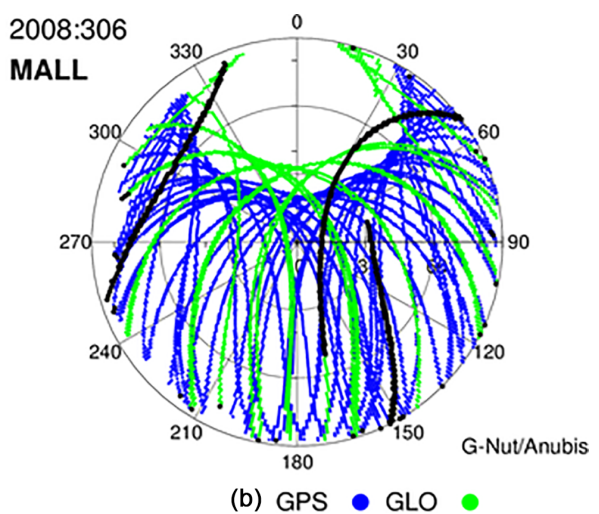

(b) GPS • GLO

Figure 6. Sky plots before (a) and after (b) replacing the malfunctioning antenna at the MALL site (30 October 2008). Blue and green dots represent GPS and GLONASS (GLO), respectively, while black dots indicate single-frequency observations.

\section{Assessment of reprocessing solutions}

The GOP variants and reprocessing models were assessed by a number of criteria, including those of the internal evaluations of repeatability of station coordinates, residuals at reference stations and the external validation of ZTDs and tropospheric horizontal gradients with data from numerical weather model reanalyses.

\subsection{Repeatability of station coordinates}

We used coordinate repeatability to assess the quality of models applied in GNSS analysis. To be as thorough as possible, we not only assessed all GOP Repro2 variants but also assessed two GOP Repro1 solutions in order to discern improvements within the new reanalyses. The two Repro1 solu- tions differed in their used reference frames and PCV models: IGS05 and IGS08.

Table 3 summarizes mean coordinate repeatability in the north, east and up components of all stations from their weekly combinations. All GOP Repro2 solution variants reached approximately 50 and $25 \%$ of the lower mean RMS of coordinate repeatability when compared to the GOP Repro1/IGS08 solution in its horizontal and vertical components, respectively. These values represent even greater improvements when compared to the GOP Repro1/IGS05 solution. Comparing these two Repro1 solutions clearly demonstrates the beneficial impact of the new PCV models and reference frames. The observed differences between Repro2 and Repro1 also indicate an overall improvement of the pro- 
Table 3. Comparison of GOP solution variants for north, east and up coordinate repeatability.

\begin{tabular}{lrrr}
\hline Solution & $\begin{array}{r}\text { North RMS } \\
(\mathrm{mm})\end{array}$ & $\begin{array}{r}\text { East RMS } \\
(\mathrm{mm})\end{array}$ & $\begin{array}{r}\text { Up RMS } \\
(\mathrm{mm})\end{array}$ \\
\hline GOP Repro1/IGS05 & 3.01 & 2.40 & 5.08 \\
GOP Repro1/IGS08 & 2.64 & 2.21 & 4.94 \\
GO0 & 1.20 & 1.30 & 4.14 \\
GO1 & 1.23 & 1.33 & 3.97 \\
GO2 & 1.24 & 1.33 & 4.01 \\
GO3 & 1.26 & 1.34 & 4.07 \\
GO4 & 1.14 & 1.24 & 3.73 \\
GO5 & 1.14 & 1.24 & 3.73 \\
GO6 & 1.14 & 1.24 & 3.73 \\
\hline
\end{tabular}

cessing software from version 5.0 to 5.2 and the enhanced quality of global precise orbit and earth orientation products.

Various GOP Repro2 solutions were also used to assess the selected models. Variants GO0 and GO1 differ in their mapping functions (GMF vs. VMF1) used to project ZTDs into slant path delays. These comparisons demonstrate that vertical component repeatability improved from 4.14 to $3.97 \mathrm{~mm}$, whereas horizontal component repeatability decreased slightly. By increasing the elevation cut-off angle from 3 to $7^{\circ}(\mathrm{GO} 2)$ and $10^{\circ}(\mathrm{GO} 3)$, we observed a slight increase in RMS from repeatability of all coordinates. This can be explained by the positive impact of low-elevation observations on the decorrelation of height and tropospheric parameters, despite the fact that applied models (such as elevationdependent weighting, PCVs, multipath) are still not optimal for including observations at very low-elevation angles. On the other hand, it should be noted that the VMF1 mapping function is particularly tuned to observations at $3^{\circ}$ elevation angle, which leads to biases at higher elevation angles (Zus et al., 2015).

The GO4 solution represents an official GOP contribution to EUREF combined products. It is identical to the variant GO1 but applies a non-tidal atmospheric loading. Steigenberger et al. (2009) discussed the importance of applying non-tidal atmospheric loading corrections together with a precise a priori ZHD (zenith hydrostatic delay) model. It has been concluded that using mean, or slowly varying, empirical pressure values for estimating a priori ZHD instead of true pressure values results in a partial compensation of atmospheric loading effects, which is the case of the GO1 solution. A positive $10 \%$ improvement in height repeatability was observed for the $\mathrm{GO} 4$ solution. Our improvement was slightly lower than in a global scope reported by Dach et al. (2011) with an improvement of 10-20\% over all stations. As the effect depends on the selected stations, a slightly higher impact in a global scale might be attributed to the station distribution, particularly differences in terms of latitude and altitude.
No impact was observed from the higher-order ionospheric effects (GO4 vs. GO5) in terms of coordinate repeatability. As the effect is systematic within the regional network (Fritsche et al., 2005), it was mostly eliminated by using reference stations in the domains of interest. The combination of tropospheric horizontal gradients from 6 to $24 \mathrm{~h}$ time resolution (GO4 vs. GO6), using the piecewise linear model, had a negligible impact on the repeatability of station coordinates too.

\subsection{Reference frame - residuals at fiducial stations}

The terrestrial reference frame (Altamimi et al., 2001) is a realization of a geocentric system of coordinates used by space geodetic techniques. To avoid a degradation of GNSS products, differential GNSS analysis methods require a proper referencing of the solution to the system applied in the generation of precise GNSS orbit products. For this purpose, we often use the concept of fiducial stations with precise coordinates well known in the requested system. Such stations are used to define the geodetic datum while their actual position can be readjusted by applying a condition minimizing coordinate residuals. No station is able to guarantee a stable position and unchanged instrumentation during the whole reprocessing period. Thus a set of about 50 stations, with more than 100 time periods for reference coordinates, was carefully prepared for datum definition in the GOP reprocessing. An iterative procedure was then applied for every day by comparing a priori reference coordinates with actually estimated ones and excluding fiducial stations exceeding differences by 5,5 and $15 \mathrm{~mm}$ in the north, east and up components.

Figure 7 shows the evolution of the number of actually used fiducial stations (represented as red dots) from all configured fiducial sites (represented as black dots) after applying an iterative procedure of validation on a daily basis. This reprocessing began with the use of 16-20 fiducial stations in 1996, and this number increased to reach a maximum of over 50 during the period from 2003 to 2011. After 2011, this number decreased, due to a common loss of reference stations available from the last realization of the global terrestrial reference frame without changes in its instrumentation. In most cases, only 2 or 3 stations were excluded from the total number; however, this number is lower for some daily solutions, indicating the removal of even more stations. The lowest number of fiducial sites (12) was identified on day 209 of the year 1999, while low numbers were generally observed at the beginning of the reprocessing period, in 1996. We observed consistent mean RMS errors for horizontal, vertical and total residuals of $6.47,10.22$ and $12.25 \mathrm{~mm}$ and $4.83,7.94$ and $9.35 \mathrm{~mm}$ for daily and weekly solutions, respectively, which demonstrate the stability of the reference system in the reprocessing. The seasonality in height coordinate estimates characterized by the RMS of residuals from the reference frame realization is dominated by errors due to 


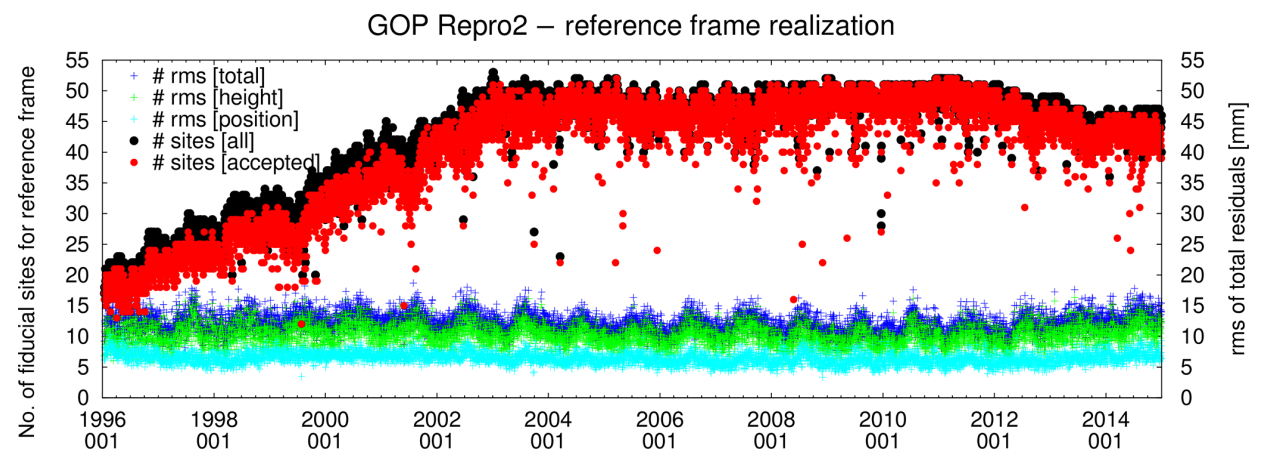

Figure 7. Statistics of the daily reference system realization: (a) RMS of residuals at fiducial stations (representing the total, height and position); (b) number of stations (all and accepted after an iterative control).

modelling of the troposphere. We believe the main contribution stems from the insufficiencies in modelling of wet tropospheric delay, as the effect has the most pronounced seasonal signal within the GNSS data analysis. Additionally, the estimated station ZTD parameters and height are difficult to decorrelate. In the next section, the strong seasonal variation in comparing zenith total delays estimated from GNSS and NWM data is clearly visible.

\subsection{Zenith total delays}

We compared all reprocessed tropospheric parameters with respect to independent data from the ERA-Interim global reanalysis (Dee et al., 2011) provided by the European Centre for Medium-Range Weather Forecasts from 1969 to the present. For the period of 1996-2014, we calculated tropospheric parameters (namely ZTD and tropospheric horizontal linear gradients) from the NWM for all EPN stations using the GFZ (German Research Centre for Geosciences) raytracing software (Zus et al., 2014). The comparison of tropospheric parameters was performed by applying the linear interpolation of GNSS parameters to the original NWM $6 \mathrm{~h}$ representation, using the GOP-TropoDB (Gyôri and Douša, 2016). For monthly statistics discussed in this section, we applied an iterative procedure for outlier detection using the $3 \sigma$ criteria calculated from the compared ZTD or gradient differences.

Table 4 summarizes comparisons of GNSS ZTDs, and tropospheric horizontal gradients, from all GOP processing variants with those obtained from the ERA-Interim. Mean biases and standard deviations were first calculated for each station and each month and then the mean and standard deviation of these values were computed, characterizing dispersions of all statistical values over the ensemble of stations.

The results in the table indicate a mean ZTD bias $-1.8 \mathrm{~mm}$ for all comparisons (GNSS-NWM) suggesting ZTDs achieved from the NWM reanalysis are drier than those obtained from GNSS reprocessing. Similar biases have been observed for all other European GNSS reprocessing products during the period of 1996-2014 (Pacione et al.,
2017). On the other hand, when processing the ERA-Interim using two different software and methodologies within the GNSS4SWEC Benchmark campaign (Douša et al., 2016) during May and June of 2013 in Central Europe, and by their comparison to two GNSS reference products based on different processing methods, we observed bias differences within $\pm 0.4 \mathrm{~mm}$ in ZTD. As neither GNSS nor NWM is able to sense the troposphere with an absolute accuracy better than the bias that we observed, we cannot make any conclusion, except for its independence from the GNSS software. A mixture of common processing aspects such as the scale of the GNSS network, applied tropospheric model, precise orbit product and others could still cause such small biases in GNSS analysis at least.

Comparing the results of the official GOP Repro2 solution (GO4) to those of the legacy solution (GO0) demonstrates an overall improvement of $9 \%$ in terms of accuracy, which corresponds to a similar comparison between the EUREF Repro1 and Repro2 products (Pacione et al., 2017). The improvement is assumed to be even larger (indicated by the coordinate repeatability) since the comparison of tropospheric parameters is limited by a lower quality of reference products derived from NWM data (Douša et al., 2016; Kačmařík et al., 2017; Bock and Nuret, 2009).

Comparing the GO1 and GO0 variants demonstrates that the VMF1 mapping function outperforms GMF in terms of the standard deviation if the elevation cut-off angle of $3^{\circ}$ is used. The change of mapping function together with the use of more accurate a priori ZHD resulted in the ZTD standard deviation improving from $8.8 \mathrm{~mm}(\mathrm{GO} 0)$ to $8.3 \mathrm{~mm}$ (GO1). However, bias was slightly increased, which could be partly attributed to the use of the mean pressure model compensating for part of the non-tidal atmospheric loading (see Sect. 5.1). Using non-tidal atmospheric loading corrections along with precise modelling of a priori ZHD contributed to a small reduction of the bias from -2.0 to $-1.8 \mathrm{~mm}$ and, mainly, to the improvement by reducing this ZTD accuracy to $8.1 \mathrm{~mm}$ (GO4). This corresponds with the previous assessment of the repeatability of station coordinates. Degrada- 
Table 4. Statistics (bias and standard deviations) of ZTD and tropospheric gradients from the seven reprocessing variants compared to those obtained from the ERA-Interim NWM reanalysis. In addition to the statistics, the $1 \sigma$ range over the ensemble of stations is provided.

\begin{tabular}{lcccccc}
\hline Solution & $\begin{array}{c}\text { ZTD bias } \\
(\mathrm{mm})\end{array}$ & $\begin{array}{c}\text { ZTD SD } \\
(\mathrm{mm})\end{array}$ & $\begin{array}{c}\text { EGRD bias } \\
(\mathrm{mm})\end{array}$ & $\begin{array}{c}\text { EGRD SD } \\
(\mathrm{mm})\end{array}$ & $\begin{array}{c}\text { NGRD bias } \\
(\mathrm{mm})\end{array}$ & $\begin{array}{c}\text { NGRD SD } \\
(\mathrm{mm})\end{array}$ \\
\hline GO0 & $-1.5 \pm 2.1$ & $8.8 \pm 2.0$ & $-0.04 \pm 0.08$ & $0.39 \pm 0.10$ & $+0.01 \pm 0.09$ & $0.43 \pm 0.12$ \\
$\mathrm{GO1}$ & $-2.0 \pm 2.1$ & $8.3 \pm 2.2$ & $-0.04 \pm 0.08$ & $0.39 \pm 0.10$ & $+0.01 \pm 0.09$ & $0.42 \pm 0.13$ \\
$\mathrm{GO} 2$ & $-1.9 \pm 2.2$ & $8.4 \pm 2.2$ & $-0.05 \pm 0.10$ & $0.41 \pm 0.10$ & $+0.00 \pm 0.12$ & $0.45 \pm 0.12$ \\
$\mathrm{GO3}$ & $-1.8 \pm 2.3$ & $8.5 \pm 2.1$ & $-0.08 \pm 0.13$ & $0.43 \pm 0.11$ & $-0.01 \pm 0.14$ & $0.49 \pm 0.12$ \\
$\mathrm{GO} 4$ & $-1.8 \pm 2.4$ & $8.1 \pm 2.1$ & $-0.04 \pm 0.09$ & $0.38 \pm 0.10$ & $+0.00 \pm 0.09$ & $0.40 \pm 0.12$ \\
GO5 & $-1.8 \pm 2.4$ & $8.1 \pm 2.1$ & $-0.05 \pm 0.09$ & $0.38 \pm 0.10$ & $+0.01 \pm 0.08$ & $0.40 \pm 0.12$ \\
GO6 & $-1.8 \pm 2.4$ & $8.2 \pm 2.1$ & $-0.04 \pm 0.08$ & $0.29 \pm 0.06$ & $+0.01 \pm 0.09$ & $0.28 \pm 0.06$ \\
\hline
\end{tabular}

tion in ZTD precision was also observed when the elevation cut-off angle was raised from 3 to $7^{\circ}(\mathrm{GO} 2)$ or $10^{\circ}(\mathrm{GO} 3)$. No impacts on ZTD were visible from additional modelling of high-order ionospheric effects (GO5) or from stacking of $6 \mathrm{~h}$ horizontal gradients into daily piecewise linear estimates (GO6).

Figure 8 displays the time series of statistics from comparisons of the GOP official ZTD product (GO4) with respect to the results of the ERA-Interim reanalysis. Mean bias and standard deviation were derived from the monthly statistics of the 6-hourly GNSS-ERA-Interim ZTD differences. A $1 \sigma$ range of the mean values, represented by error bars, are additionally derived from all stations on a monthly basis. Although the time series show homogeneous results over the given time span, a small increase in the mean standard deviation over time likely corresponds with the increasing number of EPN sites, rising from approximately 30 to 300 . The early years (1996-2001) also display a worse overall agreement in the $1 \sigma$ range of mean values over all stations, which can be attributed to the varying quality of historical observations and precise orbit products. The mean bias varies from -3 to $1 \mathrm{~mm}$ during the period of 1996-2014, with a long-term mean of $-1.8 \mathrm{~mm}$ (Table 4 ). The long-term mean is also relatively small compared to the ZTD mean $1 \sigma$ range of $3-5 \mathrm{~mm}$.

\subsection{Tropospheric horizontal linear gradients}

Additional GNSS signal delay due to the tropospheric gradients were developed by MacMillan (1995). The complete tropospheric model for the line-of-sight delay $\left(\Delta D_{\mathrm{T}}\right)$ using the parameters zenith hydrostatic delay, zenith wet delay (ZWD), and first-order horizontal tropospheric gradients $G_{N}$ and $G_{E}$, all expressed in units of length, is described as follows:

$$
\begin{aligned}
\Delta D_{\mathrm{T}} & =\mathrm{mf}_{\mathrm{h}}(e) \mathrm{ZHD}+\mathrm{mf}_{\mathrm{w}}(e) \mathrm{ZWD} \\
& +\mathrm{mf}_{\mathrm{g}}(e) \cot (e)\left[G_{N} \cos (A)+G_{E} \sin (A)\right],
\end{aligned}
$$

where $e$ and $A$ are observation elevation and azimuth angles and $\mathrm{mf}_{\mathrm{h}}, \mathrm{mf}_{\mathrm{w}}, \mathrm{mf}_{\mathrm{g}}$ are hydrostatic, wet and gradient mapping functions, respectively, representing the projection from an elevation to the zenith. Horizontal gradients should optimally represent a ZTD change in north and east directions characterized by terms $G_{N} \cot (e)$ and $G_{E} \cot (e)$ in the equation. However, the gradients need to be parameterized practically with respect to observation elevation angle instead of the distance theoretically applicable to the tropospheric effect at various elevation angles. The interpretation of the tropospheric horizontal gradients in the Bernese software represents the north and east components of angle applied for the tilting the zenith direction in the mapping function with gradients representing (in unit of length) the tilting angle multiplied by the delay in zenith (Meindl et al., 2004).

Similarly as in the case of the ZTD and coordinate assessment, Table 4 shows that tropospheric gradients became worse when raising the elevation cut-off angle from 3 to $7^{\circ}(\mathrm{GO} 2)$ or $10^{\circ}(\mathrm{GO} 3)$. Mean standard deviations of the GO2 and GO3 solutions increased by 8 and $12 \%$, respectively, which is valid for the whole period of monthly time series (not shown). No significant differences in temporal variations of mean biases of the north and east tropospheric gradient variants were identified while they shared a higher variability during the years 1996-2001. No impact of modelling of high-order ionospheric effects (GO5) was observed. Statistics of GO4 and GO6 solutions compared to the ERAInterim revealed that standard deviations dropped from 0.38 to $0.28 \mathrm{~mm}$ and from 0.40 to $0.29 \mathrm{~mm}$ for the east and north gradients, respectively. The worse performance of the GO4 solution is attributed to the fact that tropospheric horizontal gradients were estimated with a $6 \mathrm{~h}$ sampling interval using the piecewise linear model by applying practically no absolute or relative constraints. In such cases, increased correlations of the gradients with other parameters can cause instabilities in processing certain stations at specific times; the gradients absorb some remaining errors in the GNSS analysis model. The mean biases of the tropospheric gradients are considered to be negligible, but it was demonstrated in Sect. 4 that some large systematic effects were indeed discovered and attributed to the quality of GNSS signal tracking.

Figure 9 displays monthly time series of statistics from comparisons of the GNSS and NWM tropospheric horizontal 


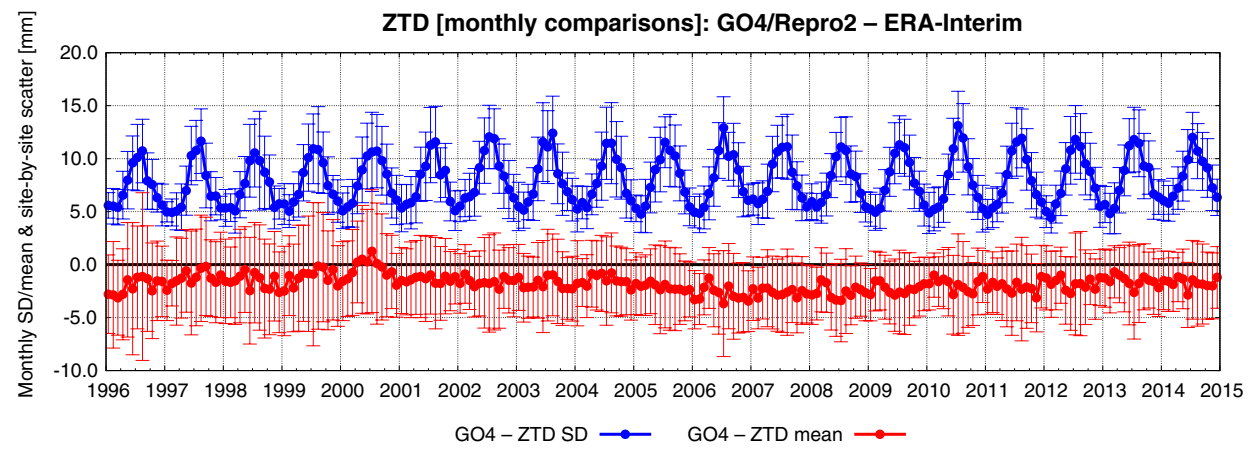

Figure 8. Monthly means of bias and standard deviation of the official GOP ZTD products compared to those of the ERA-Interim. Error bars indicate standard errors of mean values over all compared stations.
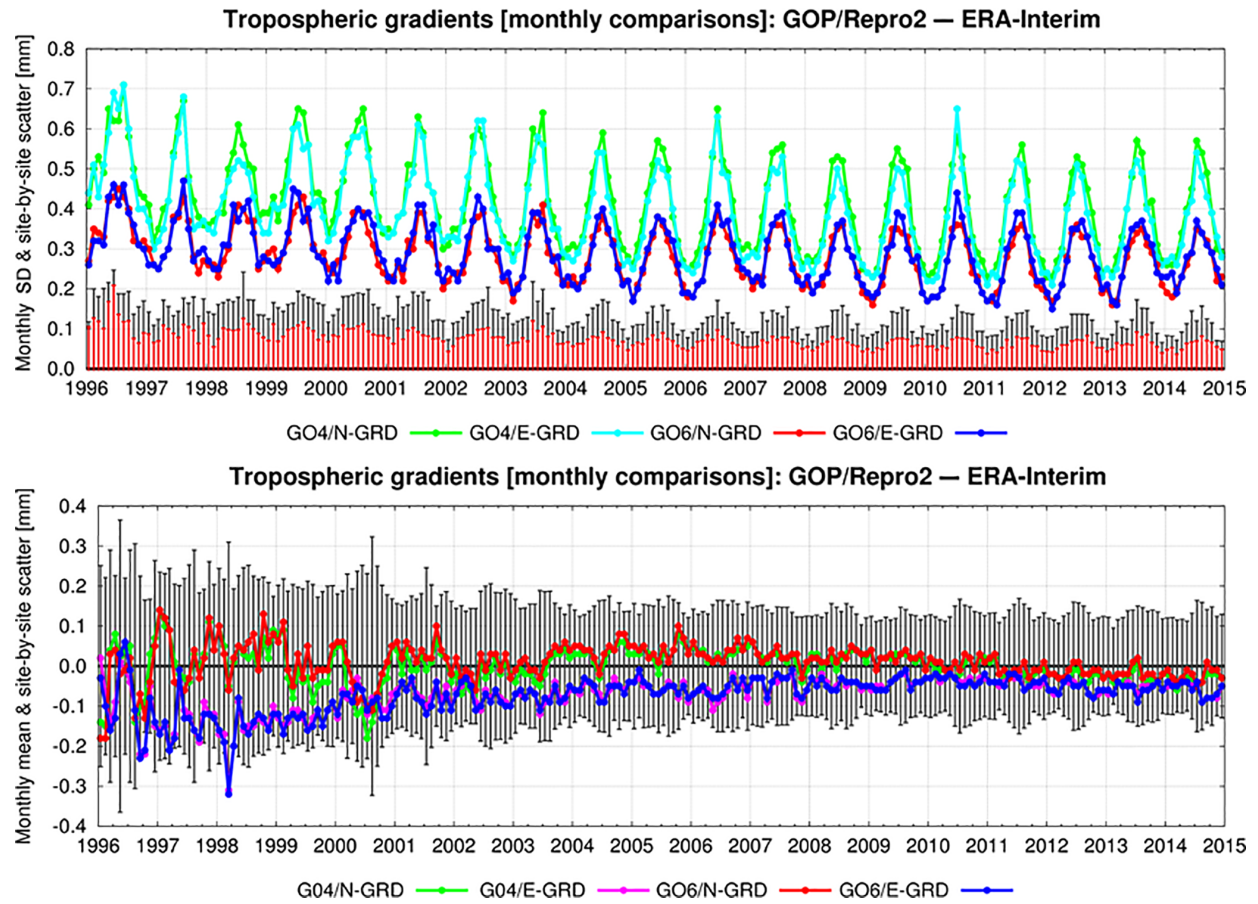

Figure 9. Monthly means of bias and standard deviation of tropospheric horizontal north (N-GRD) and east (E-GRD) gradients compared to those obtained by the ERA-Interim. Note that similar products are almost superposed. Error bars indicate standard errors of mean values over all compared stations plotted from the zero $y$ axis to emphasize seasonal variations and trends. Error bars are displayed for north gradients only; however, they are representative for the east gradients too.

gradients in the north and east directions. Two solutions are highlighted in order to demonstrate the impact of different parameter temporal resolutions: a $6 \mathrm{~h}$ resolution is used for $\mathrm{GO} 4$ and a $24 \mathrm{~h}$ resolution is used for GO6. Seasonal variations are mainly pronounced when observing mean standard deviations (top plot), whereas gradual improvement is more pronounced for mean biases (bottom plot). The reduction of the initial mean biases in horizontal gradients, and the corresponding $1 \sigma$ ranges over the values from the ensemble of stations, can be attributed to the improved availability and quality of low-elevation observation tracking. Elevation cutoff angles for collecting GNSS observations were initially configured station by station, ranging from 0 to $15^{\circ}$, until 2008 when the elevation cut-off angle $0^{\circ}$ was recommended for all the stations.

Mean standard deviations and their $1 \sigma$ ranges over all stations (Fig. 9, top plot) are lower by a factor of 1.3 for the solution with $24 \mathrm{~h}$ resolution (GO6) compared to the $6 \mathrm{~h}$ resolution (GO4); the impact is also especially pronounced in the early years of the dataset. The improvement factor ranges from 1.03 to 1.65 with the mean value of 1.35 overall stations and it is usually higher for years before 2001. Theoretically, with 4 times more observations in GO6, the standard deviation was expected to be divided by a factor of 2 . This dis- 
Table 5. Median, minimum (min) and maximum (max) values of total ZTD biases and standard deviation (SD) over all stations. Units are millimetres.

\begin{tabular}{lrrrrrr}
\hline $\begin{array}{l}\text { Compared } \\
\text { variants }\end{array}$ & $\begin{array}{r}\text { ZTD bias } \\
\text { median }\end{array}$ & $\begin{array}{r}\text { ZTD bias } \\
\text { min }\end{array}$ & $\begin{array}{r}\text { ZTD bias } \\
\text { max }\end{array}$ & $\begin{array}{r}\text { ZTD SD } \\
\text { median }\end{array}$ & $\begin{array}{r}\text { ZTD SD } \\
\text { min }\end{array}$ & $\begin{array}{r}\text { ZTD SD } \\
\text { max }\end{array}$ \\
\hline GO1-GO0 & -0.36 & -1.52 & +0.70 & 2.01 & 0.69 & 3.82 \\
GO2-GO1 & +0.03 & -0.81 & +1.66 & 0.66 & 0.15 & 1.29 \\
GO3-GO1 & +0.03 & -2.22 & +2.66 & 1.10 & 0.31 & 2.04 \\
GO4-GO1 & +0.05 & -3.29 & +5.55 & 1.37 & 0.68 & 4.72 \\
GO5-GO4 & -0.02 & -0.31 & +0.07 & 0.07 & 0.04 & 0.30 \\
GO6-GO4 & -0.02 & -0.23 & +0.16 & 1.24 & 0.76 & 2.46 \\
\hline
\end{tabular}

crepancy indicates serial correlations in errors which, among others, stem from the errors in precise products and models. Significant improvements, however, indicate possible correlations between tropospheric gradients and other estimated parameters, such as ambiguities, height and zenith total delays, and suggest a careful handling, particularly when applying a sub-daily temporal resolution.

\subsection{Spatial and temporal ZTD analysis}

We performed spatial and temporal analyses of all processed variants in order to assess the impact of different settings on tropospheric products. Zenith tropospheric delays from all variants were compared in such a way to enable the assessment of the impact of any single processing change: (1) GO1-GO0 for mapping function and a more precise a priori ZHD model, (2) GO2-GO1 and GO3-GO1 for different elevation cut-off angle, (3) GO4-GO1 for non-tidal atmospheric corrections, (4) GO5-GO4 for higher-order ionospheric corrections and (5) GO6-GO4 for temporal resolution tropospheric horizontal gradients. Station-specific behaviour will be studied in future.

Geographical maps of spatially distributed biases and standard deviations in ZTDs from all compared variants for the whole network are shown in Figs. 10 and 11. Additionally, median, minimum and maximum values of station-wise total statistics are provided in Table 5. Figures 12, 13 and 14 illustrate ZTD statistics with respect to the station latitude, ellipsoidal height and time, respectively.

Using the VMF1 mapping function together with precise a priori ZHD from VMF1 instead of the GMF and GPT models, respectively (see GO1 vs. GO0), we observe biases ranging from -1.52 to $0.70 \mathrm{~mm}$, the median value of $-0.36 \mathrm{~mm}$, and, according to Table 5, all biases indicated a moderate latitudinal dependence, see Fig. 12. Standard deviations range from 0.69 to $3.82 \mathrm{~mm}$ in Table 5, with a marked increase along with the latitude, Fig. 12, indicating the GPT performs worse at higher latitudes. This is consistent with Steigenberger et al. (2009) demonstrating a partial compensation of the atmospheric loading effect by using the GPT model. In cases where the atmospheric loading effect is not corrected for, the errors are mostly assimilated to the zenith total delay parameters if station coordinates are fixed on a weekly basis. Additionally, Fig. 14 shows that the standard deviation grows with time, which might be explained by the increased number of low-elevation observations with time in the EUREF Permanent Network as demonstrated for the WTZR (Wettzell) station in Fig. 15.

Biases obtained from the comparison of different elevation cut-off angles, i.e. variants 3 to $7^{\circ}(\mathrm{GO} 2-\mathrm{GO} 1)$ and 3 to $10^{\circ}$ (GO3-GO1), range from -0.81 to $1.66 \mathrm{~mm}$ and from -2.22 to $2.66 \mathrm{~mm}$, respectively, and standard deviations range from 0.15 to $1.29 \mathrm{~mm}$ and from 0.31 to $2.04 \mathrm{~mm}$, see Table 5. Generally, the impact of the different elevation cut-off angle does not reveal any biases with respect to the latitude (Fig. 12) or the station height (Fig. 13). As expected, the impact is larger for the GO3-GO1 differences and particularly affected some stations. Yearly biases exceeding $\pm 2.5 \mathrm{~mm}$ were identified for the BELL, DENT, MLVL, MOPS, POLV RAMO and SBG2 stations. Temporal dependencies in the GO2-GO1 and GO3-GO1 comparisons, Fig. 14, show that the scatter of station-specific biases steadily grows in time, which is assumed to be related to the higher availability of low-elevation observations. On the other hand, a small impact is observed for the standard deviation compared to the other studied effects. This indicates the elevation cut-off angle affects mainly ZTD biases, which has been also reported by Ning and Elgered (2012).

Table 5 shows that biases due to the non-tidal atmospheric loading (GO4-GO1) range from -2.29 to $5.55 \mathrm{~mm}$, which is one of the largest impacts compared to other comparison variants, and standard deviations range from 0.68 to $4.72 \mathrm{~mm}$, which represents the second largest impact compared to all other variants. A standard deviation larger than $3 \mathrm{~mm}$ was observed at some stations, such as JOZE, MAD2, MADR, MDVO, MOPI, NYAL, SBG2, VENE and WETT. It should be emphasized this comparison reflects differences due to the modelling of atmospheric loading corrections in GO4 and a partial compensation of the loading effect by zenith tropospheric delay estimates in the GO1 solution variant. The differences are strongly station dependent, but they did not reveal any dependence on latitude, see Fig. 12. This shows, however, some degradation in standard deviation during the first years of the reprocessing, see Fig. 14. Since a 

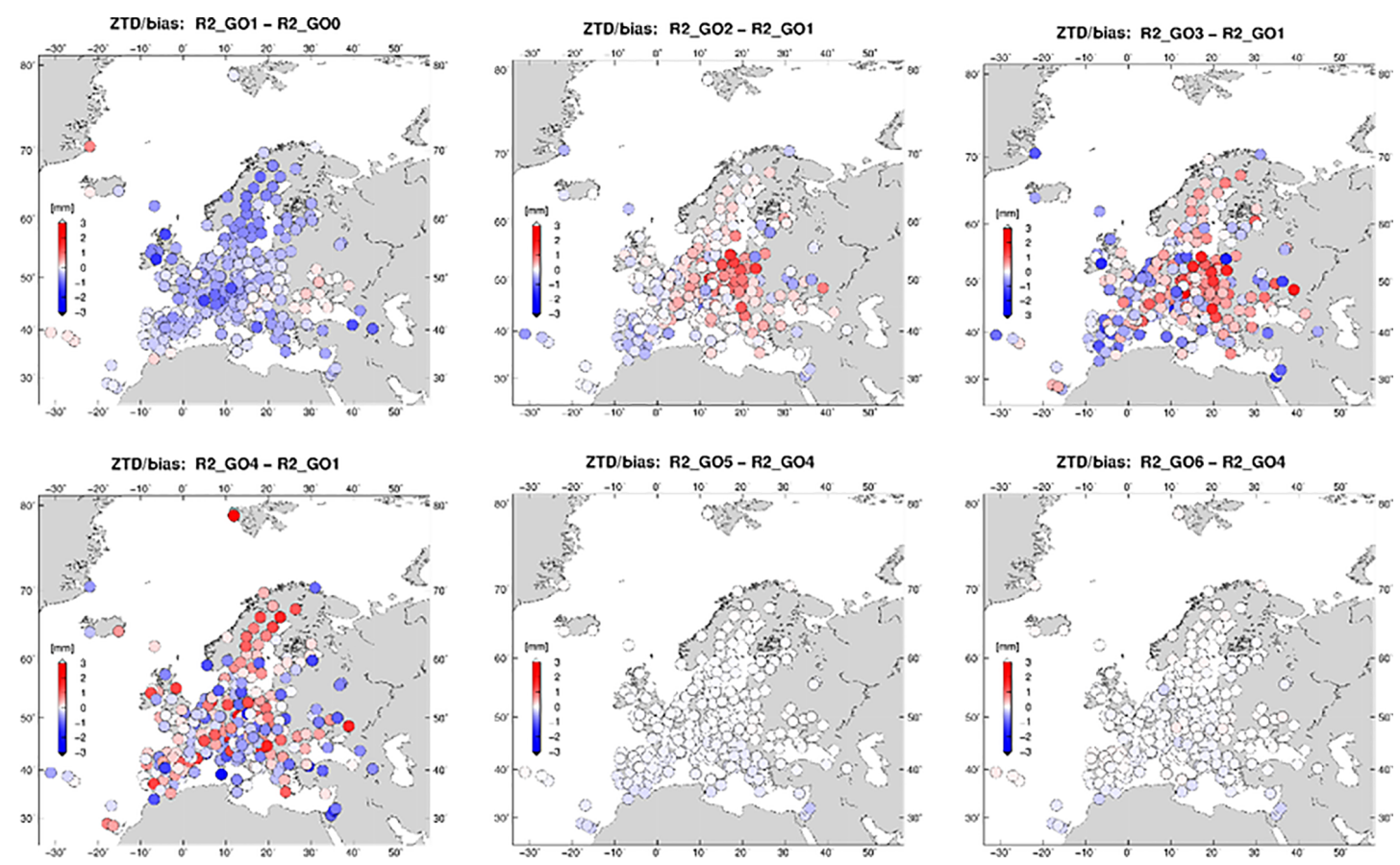

Figure 10. Geographic visualization of biases from inter-comparisons of the GOP second reprocessing variants.
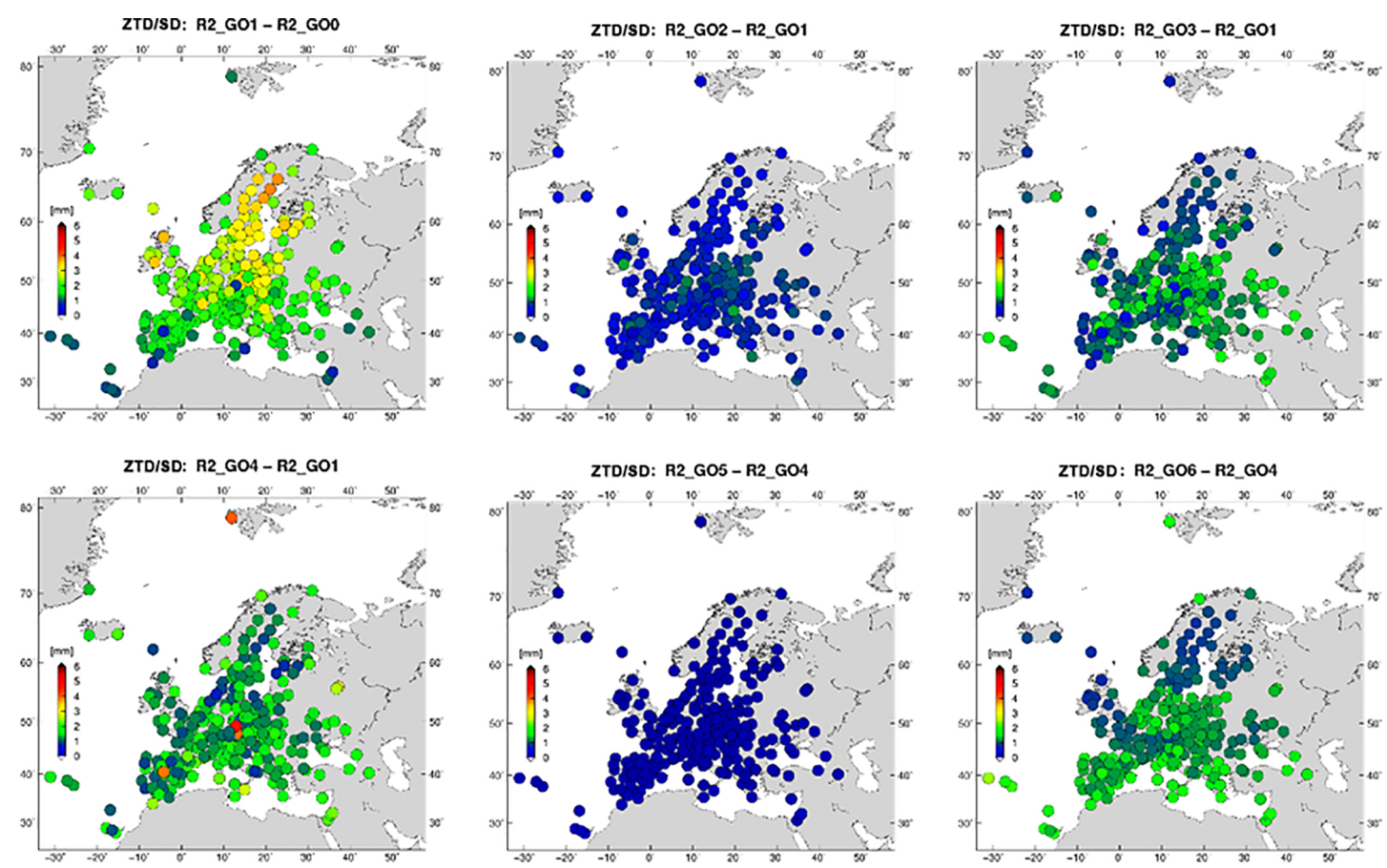

Figure 11. Geographic visualization of standard deviations from inter-comparisons of the GOP second reprocessing variants.

similar degradation in terms of standard deviations has not been observed for other comparison variants, it can be related to the quality of pressure data used to compute atmospheric loading.
The impact of the higher-order ionospheric effect (GO5GO4) is negligible at all stations, demonstrating total statistics for all stations within $\pm 0.3 \mathrm{~mm}$ when applying the $y$ range about 10 times smaller than in other panels of Figs. 12, 13 and 14. A strong latitudinal dependence is clearly visible 

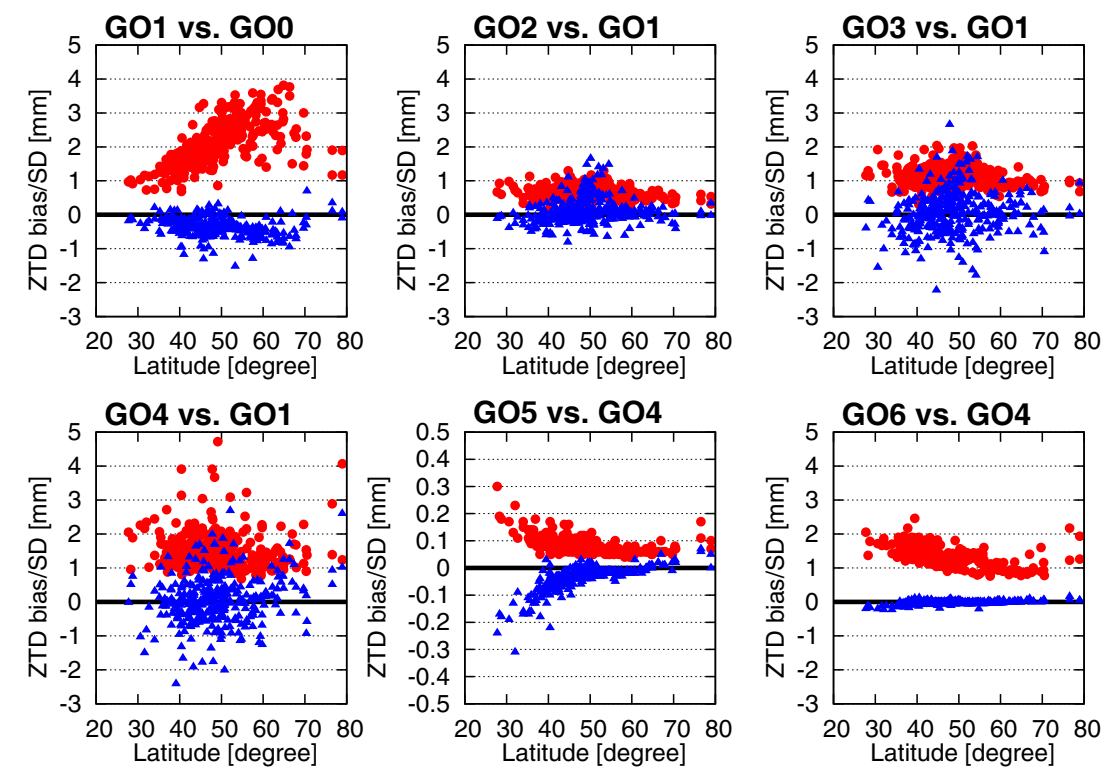

Figure 12. Dependence of ZTD biases (blue) and standard deviations (red) from inter-comparisons of the GOP second reprocessing solution variants on station latitude. Note the different $y$ range for the GO5 vs. GO4 comparison.
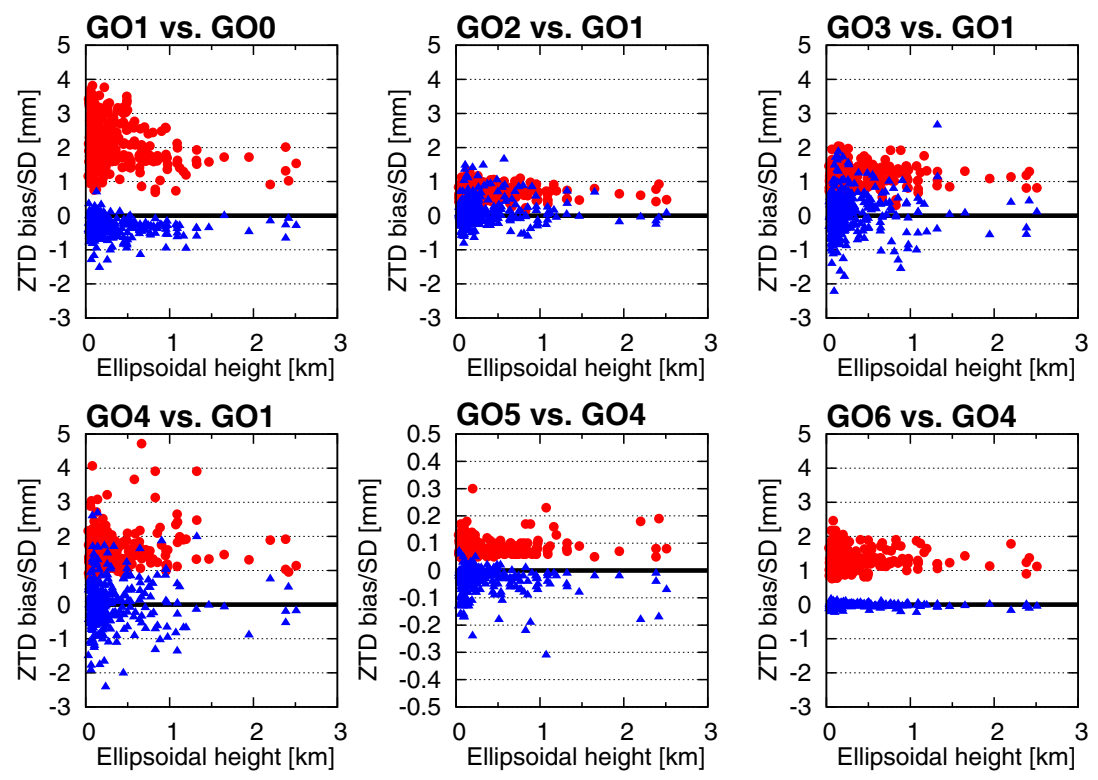

Figure 13. Dependence of ZTD biases (blue) and standard deviations (red) from inter-comparisons of the GOP second reprocessing solution variants on station ellipsoidal height. Note the different $y$ range for the GO5 vs. GO4 comparison.

in Fig. 12 as well as a temporal variability showing peaks up to $\pm 0.4 \mathrm{~mm}$, Fig. 14. Both dependencies are due to the changing magnitude of ionospheric corrections, generally increasing towards the equator along with quasi-periodic cycles of the solar magnetic activity, reaching peaks around years 2001 and 2014.

The impact of stacking tropospheric gradients from $6 \mathrm{~h}$ to daily estimates (GO6-GO4) is almost negligible in terms of biases which stay below $\pm 1 \mathrm{~mm}$, Table 5 and Fig. 10. How- ever, standard deviations range from 0.76 to $2.46 \mathrm{~mm}$ and grow towards the equator, Fig. 12. That can be certainly attributed to the more difficult modelling of a local asymmetry in the troposphere, which generally increases together with the increasing of the water vapour content. No significant temporal variation is visible for the bias, but a small decrease is observed for the standard deviation (Fig. 14). This can be attributed to a higher stability of the gradient estimates with 

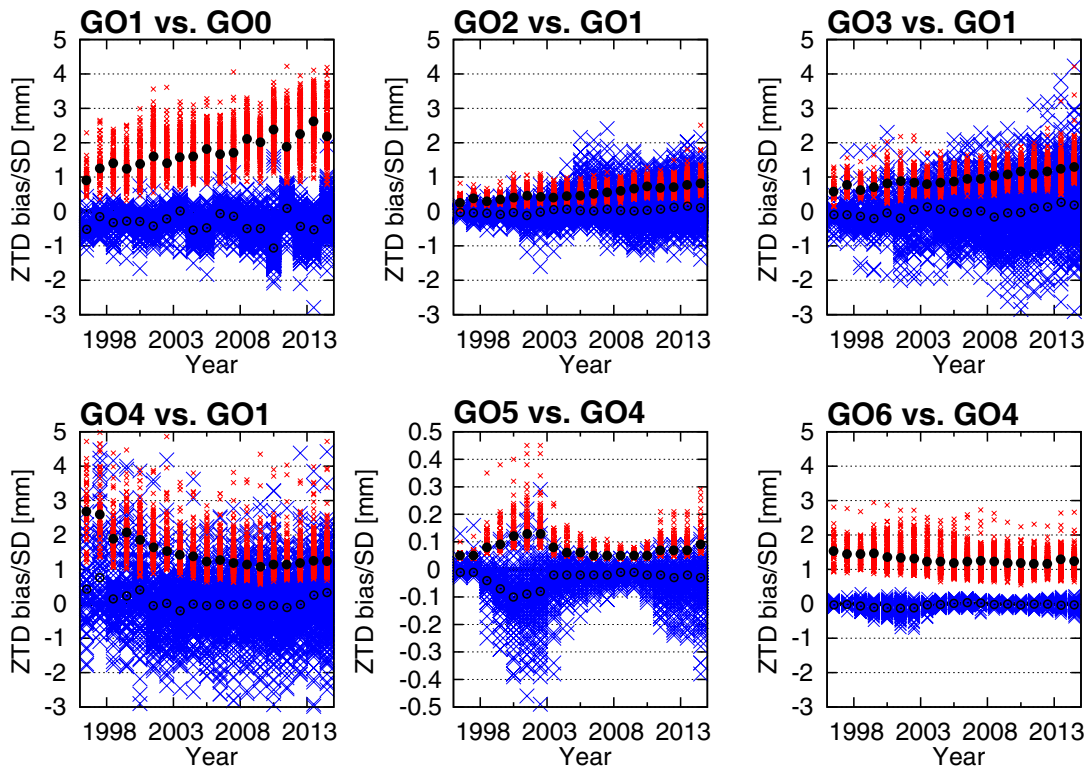

Figure 14. Dependence of ZTD biases (blue), mean biases (unfilled black circles), standard deviations (red) and mean standard deviations (filled black circles) from inter-comparisons of the GOP second reprocessing solution variants per year. Note the different $y$ range for the GO5 vs. GO4 comparison.

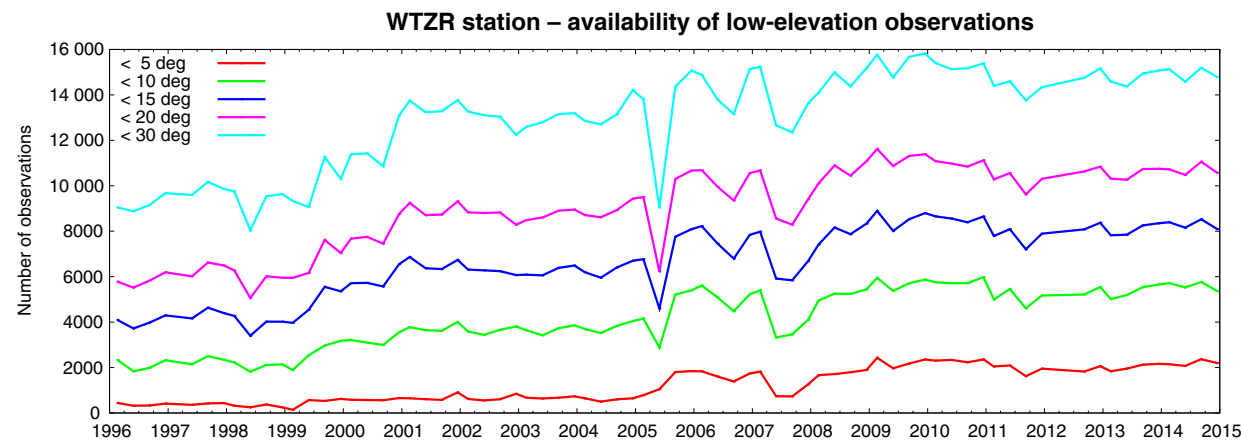

Figure 15. Availability of observations at low-elevation angles (below 5, 10, 15, 20 and $30^{\circ}$ ) for the WTZR station.

time, see Fig. 9, when supported with an increased number of available low-elevation observations.

\section{Impact of variants on long-term ZTD trend estimates}

We assessed the impact of solution variants on long-term ZTD trend estimates by analysing 172 EUREF stations providing a time series of data longer than 10 years. For each station, the trend analysis was performed without any data homogenization or outlier rejection as our focus was only on assessing the impact of solution variants on the trend estimates. The ZTD trends were estimated using the least squares regression method applied on the model (Weatherhead et al., 1998):

$Y_{\mathrm{t}}=\mu+\beta X_{\mathrm{t}}+S_{\mathrm{t}}+\varepsilon_{\mathrm{t}}$, where $\mu$ is the constant term of the model; $\beta X_{\mathrm{t}}$ is the linear trend function, with $\beta$ representing the trend magnitude; $S_{\mathrm{t}}$ represents the term modelled by the sine wave function of time $X_{\mathrm{t}}$ including annual, second harmonics and daily variations; and finally $\varepsilon_{t}$ is the noise in the data.

Site-by-site-estimated ZTD trends from all the variants are provided in the Supplement completed by time span information, number of records and estimated mean formal errors calculated over all variants. In total, trends range from -0.99 to $0.96 \mathrm{~mm}$ year $^{-1}$. Although the individual station trend provided in the Supplement could be compared to other studies - e.g. Baldysz et al. (2016), Klos et al. (2016), or Nilsson and Elgered (2008) - it should be strongly emphasized here that our trends are estimated without any preceding time-series homogenization and the formal errors of the trend estimates are underestimated by a factor 2-4 (Nilsson and Elgered, 2008). 


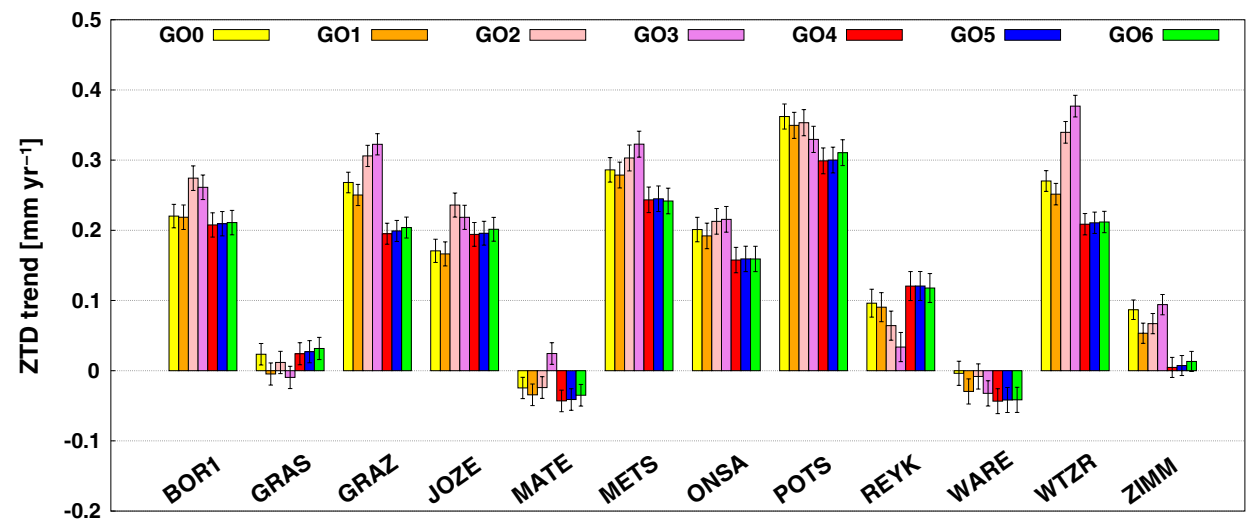

Figure 16. Long-term ZTD trend estimates and their formal errors (error bars) for all processing variants.

Table 6. Mean statistics of ZTD trend differences estimated between variants for 172 stations. Units are mm year ${ }^{-1}$.

\begin{tabular}{lrrrrrr}
\hline Statistics & GO1-GO0 & GO2-GO1 & GO3-GO1 & GO4-GO1 & GO5-GO4 & GO6-GO4 \\
\hline Min & -0.118 & -0.141 & -0.308 & -0.547 & -0.017 & -0.038 \\
Max & 0.045 & 0.179 & 0.331 & 0.452 & 0.031 & 0.036 \\
Mean & 0.036 & 0.018 & 0.012 & -0.048 & 0.007 & 0.001 \\
SD & 0.081 & 0.160 & 0.319 & 0.499 & 0.024 & 0.037 \\
\hline
\end{tabular}

Table 6 summarizes the statistics of estimated trend differences at all 172 stations, always between particular variants as defined in Sect. 5.5. Interestingly, the most significant impact is observed due to the non-tidal atmospheric loading effects reaching differences below $\pm 0.55 \mathrm{~mm}_{\text {year }}{ }^{-1}$ in ZTD trends for some extreme cases from the ensemble of 172 stations and an overall $1 \sigma$ scatter of $0.50 \mathrm{~mm}_{\text {year }}{ }^{-1}$ from the ensemble of stations. Changes in elevation cut-off angle, particularly from 3 to $10^{\circ}$, also reveal a significant impact characterized by differences below $\pm 0.34 \mathrm{~mm}_{\text {year }}{ }^{-1}$ and the scatter of $0.32 \mathrm{~mm} y e a r^{-1}$. The impact of mapping function on trend estimates remains small, with a maximum difference of $0.12 \mathrm{~mm}_{\text {year }}{ }^{-1}$ and the $1 \sigma$ scatter below $0.08 \mathrm{~mm}_{\text {year }}{ }^{-1}$, while other strategy changes, due to time resolution of tropospheric gradients and higherorder ionospheric effects, remain negligible, always below $\pm 0.04 \mathrm{~mm}$ year $^{-1}$ for all 172 stations, with the scatter of the same magnitude. All mean biases over differences also stay below $0.05 \mathrm{~mm}_{\text {year }}{ }^{-1}$. These results are consistent with a study performed by Ning and Elgered (2012) spanning a broader span of cut-off angles. They demonstrated a significant impact of this parameter on integrated water vapour trend estimates.

Finally, we selected 12 stations available over the entire second reprocessing period. All estimated trends are displayed in Fig. 16, ranging from -0.05 to $0.38 \mathrm{~mm}_{\text {year }}{ }^{-1}$. Consistent with the overall results reported in Table 5, the most significant impact for the selected 12 stations is observed in the change of elevation cut-off angle ( $\mathrm{GO} 2$ and
GO3 vs. GO1) and atmospheric loading (GO4 vs. GO1) when reaching differences up to $0.1 \mathrm{~mm}$ year $^{-1}$ in estimated ZTD trends. Impacts of other strategies are generally below $0.05 \mathrm{~mm}$ year $^{-1}$ - variants GO4, GO5 and GO6 are very similar, but not consistent again with GO1, meaning the nontidal atmospheric loading has a significant impact on trend estimates for selected stations with the longest data time series.

\section{Conclusions}

In this paper, we present results of the new GOP reanalysis of all stations within the EUREF Permanent Network during the period of 1996-2014. This reanalysis was completed during the second EUREF reprocessing to support the realization of a new European Terrestrial Reference System. In the second reprocessing, we focused on analysing a new product - the GNSS tropospheric parameter time series for applications to climate research. To achieve this goal, we improved our strategy for combining tropospheric parameters during midnights and week breaks. We also performed seven solution variants to study optimal troposphere modelling; we assessed each of these variants in terms of their coordinate repeatability by using internal evaluations of the applied models and strategies. We also compared tropospheric ZTD and tropospheric horizontal gradients with independent evaluations obtained by numerical weather reanalysis via the ERA-Interim.

Results of the GOP Repro2 yielded improvements of approximately 50 and $25 \%$ for their horizontal and verti- 
cal component repeatability, respectively, when compared to those of the GOP Repro1 solution. Vertical repeatability was reduced from 4.14 to $3.73 \mathrm{~mm}$ when using the VMF1 mapping function, a priori ZHD, and non-tidal atmospheric loading corrections from actual weather data. Increasing the elevation cut-off angle from 3 to $7^{\circ} / 10^{\circ}$ increased RMS errors of residuals from these coordinates' repeatability. All of these factors were also confirmed by the independent assessment of tropospheric parameters using NWM reanalysis data.

We particularly recommend using low-elevation observations along with the VMF1 mapping function as well as using precise a priori ZHD values together with the consistent model of non-tidal atmospheric loading. While estimating tropospheric horizontal linear gradients improves coordinates' repeatability, $6 \mathrm{~h}$ sampling without any absolute or relative constraints revealed a loss of stability due to their correlations with other parameters. On the other hand, $24 \mathrm{~h}$ piecewise linear gradients did not indicate a worse repeatability of coordinates estimates. For saving the time needed for the processing of 4 times fewer gradient parameters, we could recommend using the unconstrained $24 \mathrm{~h}$ piecewise model for the modelling of the first-order tropospheric asymmetry.

The impact of processing variants on long-term ZTD trend estimates was assessed at 172 EUREF stations with time series longer than 10 years. The most significant impact was observed due to the non-tidal atmospheric loading effect reaching differences below $\pm 0.55 \mathrm{~mm}_{\text {year }}{ }^{-1}$ in ZTD trends for some extreme cases from the ensemble of 172 stations. Changes in elevation cut-off angle, particularly from 3 to $10^{\circ}$, also revealed a significant impact reaching differences below $\pm 0.35 \mathrm{~mm}_{\text {year }}{ }^{-1}$. The change of mapping function was observed to be rather small, with a maximum difference of $0.12 \mathrm{~mm}_{\text {year }}{ }^{-1}$, while other strategy changes, due to time resolution of tropospheric gradients and higherorder ionospheric effects, remained negligible, always below $\pm 0.04 \mathrm{~mm}$ year $^{-1}$ for all 172 stations.

Assessing the tropospheric horizontal gradients with respect to the ERA-Interim reanalysis data revealed some longterm systematic behaviour linked to degradation in antenna tracking quality. We presented an extreme case at the Mallorca station, in which gradients systematically increased up to $5 \mathrm{~mm}$ from 2003 to 2008 while pointing in the direction of prevailing observations at low-elevation angles. However, these biases disappeared when the malfunctioning antenna was replaced. More cases similar to this, although less extreme, have indicated that estimated tropospheric gradients are extremely sensitive to the quality of GNSS antenna tracking, thus suggesting that these gradients can be used to identify problems with GNSS data tracking in historical archives.

One of the main difficulties faced during the second reprocessing was that of the quality of the historical data, which contains a large variety of problems. We removed data that caused significant problems in network processing when these could not be pre-eliminated from normal equations dur- ing the combination process without still affecting daily solutions. To provide high-accuracy, high-resolution GNSS tropospheric products, the elimination of such problematic data or stations is even more critical considering the targeting static coordinates on a daily or weekly basis for the maintenance of the reference frame or the derivation of a velocity field. Before undertaking the third EUREF reprocessing, which is expected to begin after significant improvements have been made to state-of-the-art models, products and software, we need to improve data quality control and clean the EUREF historical archive in order to optimize any future reprocessing efforts and to increase the quality of tropospheric products. These efforts should also include the collection and documentation of all available information from each step of the second EUREF reprocessing, including individual contributions, EUREF combinations, time-series analyses and coordinates, and independent evaluations of tropospheric parameters.

Data availability. All processed reprocessed GNSS data are available at ftp://epncb.oma.be/pub/obs/, where they are maintained by the historical EPN archive of the Royal Observatory of Belgium. The official second GOP EUREF reprocessing solution (GO4) in SINEX and SINEX_TRO formats are publicly available at ftp://igs.bkg.bund.de/EPNrepro2/products/. Additionally, the tropospheric parameters for all EPN stations are available via the GOPTropDB download service at http://www.pecny.cz/GOP-TropDB/ data-download.

\section{The Supplement related to this article is available online at https://doi.org/10.5194/amt-10-3589-2017-supplement.}

Author contributions. JD and PV performed the second GOP European GNSS reprocessing. ME performed a long-term trend analysis for all the variants of the reprocessing. JD prepared the manuscript with the support of PV and ME, who particularly contributed to Sect. 6. All authors approved the final manuscript before its submission.

Competing interests. The authors declare that they have no conflict of interest.

Special issue statement. This article is part of the special issue "Advanced Global Navigation Satellite Systems tropospheric products for monitoring severe weather events and climate (GNSS4SWEC) (AMT/ACP/ANGEO inter-journal SI)". It is not associated with a conference.

Acknowledgements. The reprocessing effort and its evaluations were supported by the Ministry of Education, Youth and Science, 
the Czech Republic (projects LD14102 and LO1506). We thank two anonymous reviewers and Olivier Bock for their comments and suggestions which helped us to improve the manuscript.

Edited by: Olivier Bock

Reviewed by: two anonymous referees

\section{References}

Altamimi, Z., Angermann, D., Argus, D., Blewitt, G., Boucher, C., Chao, B., Drewes, H., Eanes, R., Feissel, M., Ferland, R., Herring, T., Holt, M., Johannson, J., Larson, K., Ma, C., Manning, J., Meertens, C., Nothnagel, A., Pavlis, E., Petit, G., Ray, J., Ries, J., Scherneck, H.-G., Sillard, P., and Watkins, M.: The terrestrial reference frame and the dynamic Earth, EOS, Transacttions, American Geophysical Union, 82, 273-279, 2001.

Baldysz, Z., Nykiel, G., Araszkiewicz, A., Figurski, M., and Szafranek, K.: Comparison of GPS tropospheric delays derived from two consecutive EPN reprocessing campaigns from the point of view of climate monitoring, Atmos. Meas. Tech., 9, 4861-4877, https://doi.org/10.5194/amt-9-4861-2016, 2016.

Bevis, M., Businger, S., Chiswell, S., Herring, T. A., Anthes, R. A., Rocken, C., and Ware R. H.: GPS Meteorology: Mapping Zenith Wet Delays onto Precipitable Water, J. Appl. Meteorol., 33, 379386, https://doi.org/10.1175/1520-0450, 1994.

Bock, O. and Nuret, M.: Verification of NWP model analyses and radiosonde humidity data with GPS precipitable water vapor estimates during AMMA, Weather Forecast., 24, 1085-1101, https://doi.org/10.1175/2009WAF2222239.1, 2009.

Bock, O., Willis, P., Wang, J., and Mears, C.: A highquality, homogenized, global, long-term (1993-2008) DORIS precipitable water data set for climate monitoring and model verification, J. Geophys. Res.-Atmos., 119, 7209-7230, https://doi.org/10.1002/2013JD021124, 2014.

Bock, O., Bosser, P., Pacione, R., Nuret, M., Fourrié, N., and Parracho, A.: A high-quality reprocessed ground-based GPS dataset for atmospheric process studies, radiosonde and model evaluation, and reanalysis of HyMeX Special Observing Period, Q. J. Roy. Meteor. Soc., 142, 56-71, https://doi.org/10.1002/qj.2701, 2016.

Böhm, J., Niell, A. E., Tregoning, P., and Schuh, H.: 2006, Global Mapping Functions (GMF): A new empirical mapping function based on numerical weather model data, Geophys. Res. Lett., 33, L07304, https://doi.org/10.1029/2005GL025546, 2006a.

Böhm, J., Werl, B., and Schuh, H.: Troposphere mapping functions for GPS and very long baseline interferometry from European Centre for Medium-Range Weather Forecasts operational analysis data. J. Geophys. Res., 111, B02406, https://doi.org/10.1029/2005JB003629, 2006b.

Bruyninx, C., Habrich, H., Söhne, W., Kenyeres, A., Stangl, G., and Völksen, C.: Enhancement of the EUREF Permanent Network Services and Products, Geodesy for Planet Earth, IAG Symposia Series, 136, 27-35, https://doi.org/10.1007/978-3-642-203381_4, 2012.

Dach, R., Böhm, J., Lutz, S., Steigenberger, P., and Beutler, G.: Evaluation of the impact of atmospheric pressure loading modeling on GNSS data analysis, J. Geodynam., 85, 75-91, https://doi.org/10.1007/s00190-010-0417-z, 2011.
Dach, R., Schaer, S., Lutz, S., Baumann, C., Bock, H., Orliac, E., Prange, L., Thaller, D., Mervart, L., Jäggi, A., Beutler, G., Brockmann, E., Ineichen, D., Wiget, A., Weber, G., Habrich, H., Söhne, W., Ihde, J., Steigenberger, P., and Hugentobler, U.: CODE IGS Analysis Center Technical Report 2013, edited by: Dach, R. and Jean, Y., IGS 2013 Tech. Rep., 21-34, 2014.

Dach, R., Lutz, S., Walser, P., and Fridez, P. (Eds.): Bernese GNSS Software Version 5.2. User manual, Astronomical Institute, University of Bern, Bern Open Publishing, 2015.

Dee, D. P., Uppala, S. M., Simmons, A. J., Berrisford, P., Poli, P., Kobayashi, S., Andrae, U., Balmaseda, M. A., Balsamo, G., Bauer, P., Bechtold, P., Beljaars, A. C. M., van de Berg, L., Bidlot, J., Bormann, N., Delsol, C., Dragani, R., Fuentes, M., Geer, A. J., Haimberger, L., Healy, S. B., Hersbach, H., Hólm, E. V., Isaksen, L., Kållberg, P., Köhler, M., Matricardi, M., McNally, A. P., Monge-Sanz, B. M., Morcrette, J.-J., Park, B.-K., Peubey, C., de Rosnay, P., Tavolato, C., Thépaut, J.-N., and Vitart, F.: The ERA-Interim reanalysis: Configuration and performance of the data assimilation system, Q. J. Roy. Meteorol. Soc., 137, 553597, https://doi.org/10.1002/qj.828, 2011.

Douša, J. and Václavovic, P.: Results of GPS Reprocessing campaign (1996-2011) provided by Geodetic observatory Pecný, Geoinformatics, FCE CTU, 9, 77-89, https://doi.org/10.14311/gi.9.7, 2012.

Douša, J., Dick, G., Kacmarík, M., Brožková, R., Zus, F., Brenot, H., Stoycheva, A., Möller, G., and Kaplon, J.: Benchmark campaign and case study episode in central Europe for development and assessment of advanced GNSS tropospheric models and products, Atmos. Meas. Tech., 9, 2989-3008, https://doi.org/10.5194/amt-9-2989-2016, 2016.

Douša, J., Böhm, O., Byram, S., Hackman, C., Deng Z., Zus, F., Dach, R., and Steigenberger, P.: Evaluation of GNSS reprocessing tropospheric products using GOP-TropDB, IGS Workshop 2016, Sydney, 8-12 February 2017, available at: http://www.igs. org/assets/pdf/W2016-PS0303-Dousa.pdf, last access: September 20172017.

Dow, J. M., Neilan, R. E., and Rizos, C.: The International GNSS Service in a changing landscape of Global Navigation Satellite Systems, J. Geod., 83, 191-198, https://doi.org/10.1007/s00190008-0300-3, 2009.

Fritsche, M., Dietrich, R., Knofel, C., Rlke, A., Vey, S., Rothacher, M., and Steigenberger, P.: Impact of higher-order ionospheric terms on GPS estimates. Geophys. Res. Lett., 32, L23311, https://doi.org/10.1029/2005GL024342, 2005.

Guerova, G., Jones, J., Douša, J., Dick, G., de Haan, S., Pottiaux, E., Bock, O., Pacione, R., Elgered, G., Vedel, H., and Bender, M.: Review of the state of the art and future prospects of the groundbased GNSS meteorology in Europe, Atmos. Meas. Tech., 9, 5385-5406, https://doi.org/10.5194/amt-9-5385-2016, 2016.

Győri, G. and Douša, J.: GOP-TropDB developments for tropospheric product evaluation and monitoring - design, functionality and initial results, IAG Symposia Series, Springer, 143, 595-602, 2016.

IERS Conventions: Gérard, P., and Luzum, B. (Eds.): IERS Technical Note No. 36, Frankfurt am Main, Verlag des Bundesamts für Kartographie und Geodäsie, 179 pp., 2010.

Ihde, J., Habrich, H., Sacher, M., Sohne, W., Altamimi, Z., Brockmann, E., Bruyninx, C., Caporali, A., Dousa, J., Fernandes, R., Hornik, H., Kenyeres, A., Lidberg, M., Makinen, J., Poutanen, 
M., Stangl, G., Torres, J. A., and Volksen, C.: EUREF's Contribution to National, European and Global Geodetic Infrastructures, in: Earth on the Edge: Science for a Sustainable Planet, edited by: Rizos, C. and Willis, P., IAG Symposia Series, Springer, 139, 189-196, https://doi.org/10.1007/978-3-642-37222-3_24, 2014.

Kacmarík, M., Douša, J., Dick, G., Zus, F., Brenot, H., Möller, G., Pottiaux, E., Kaplon, J., Hordyniec, P., Václavovic, P., and Morel, L.: Inter-technique validation of tropospheric slant total delays, Atmos. Meas. Tech., 10, 2183-2208, https://doi.org/10.5194/amt-10-2183-2017, 2017.

Klos, A., Hunegnaw, A., Teferle, F. N., Abraha, K. E., Ahmed, F., and Bogusz, J.: Noise characteristics in Zenith Total Delay from homogeneously reprocessed GPS time series, Atmos. Meas. Tech. Discuss., https://doi.org/10.5194/amt-2016-385, 2016.

Li, X., Zus, F., Lu, C., Ning, T., Dick, G., Ge, M., Wickert, J., and Schuh, H.: Retrieving high-resolution tropospheric gradients from multiconstellation GNSS observations, Geophys. Res. Lett., 42, 4173-4181, https://doi.org/10.1002/2015GL063856, 2015.

MacMillan, D. S.: Atmospheric gradients from very long baseline interferometry observations, Geophys. Res. Lett., 22, 10411044, https://doi.org/10.1029/95GL00887, 1995.

Meindl, M., Schaer, S., Hugentobler, U., and Beutler, G.: Tropospheric Gradient Estimation at CODE: Results from Global Solutions, J. Meteorol. Soc. Jpn., 82, 331-338, 2004.

Morel, L., Pottiaux, E., Durand, F., Fund, F., Follin, J. M., Durand, S., Bonifac, K., Oliveira, P. S., van Baelen, J., Montibert, C., Cavallo, T., Escaffit, R., and Fragnol, L.: Global validity and behaviour of tropospheric gradients estimated by GPS, presentation at the 2nd GNSS4SWEC Workshop held in Thessaloniki, Greece, 11-14 May 2015.

Nilsson, T. and Elgered, G., Long-term trends in the atmospheric water vapor content estimated from groundbased GPS data, J. Geophys. Res., 113, D19101, https://doi.org/10.1029/2008JD010110, 2008.

Ning, T.: GPS Meteorology: With Focus on Climate Applications, PhD Thesis, Dept. Earth and Space Sciences, Chalmers University of Technology, 2012.

Ning, T. and Elgered, E.: Trends in the atmospheric water vapor content from ground-based GPS: The impact of the elevation cutoff angle, IEEE J. Sel. Top. Appl., 5, 744-751, https://doi.org/10.1109/JSTARS.2012.2191392, 2012.
Pacione, R., Araszkiewicz, A., Brockmann, E., and Dousa, J.: EPN-Repro2: A reference GNSS tropospheric data set over Europe, Atmos. Meas. Tech., 10, 1689-1705, https://doi.org/10.5194/amt-10-1689-2017, 2017.

Steigenberger, P., Böhm, J., and Tesmer, V.: Comparison of GMF/GPT with VMF1/ECMWF and implications for atmospheric loading, J. Geodynam., 83, 943, https://doi.org/10.1007/s00190-009-0311-8, 2009.

Václavovic, P. and Douša, J.: G-Nut/Anubis - open-source tool for multi-GNSS data monitoring, in: IAG 150 Years, edited by: Rizos, Ch. and Willis, P., IAG Symposia Series, Springer, 143, 775782, https://doi.org/10.1007/1345_2015_97, 2016.

Völksen, C.: An update on the EPN Reprocessing Project: Current Achievements and Status, Presented at the EUREF 2011 Symposium, Chisinau, Republic of Moldova, 25-28 May, available at: http://www.epncb.oma.be/_documentation/ papers/eurefsymposium2011/an_update_on_epn_reprocessing_ project_current_achievement_and_status (last access: September 2017), 2011.

Weatherhead, E. C., Reinsel, G. C., Tiao, G. C., Meng, X.-L., Choi, D., Cheang, W.-K., Keller, T., DeLuisi, J., Wuebbles, D. J., Kerr, J. B., Miller, A. J., Oltmans, S. J., and Frederick J. E.: Factors affecting the detection of trends: Statistical considerations and applications to environmental data, J. Geophys. Res., 103, 1714917161, https://doi.org/10.1029/98JD00995, 1998.

Yuan, L. L., Anthes, R. A., Ware, R. H., Rocken, C., Bonner, W. D., Bevis, M. G., and Businger, S.: Sensing Climate Change Using the Global Positioning System, J. Geophys. Res., 98, 1492514937, 1993.

Zus, F., Dick, G., Heise, S., Dousa, J., and Wickert, J.: The rapid and precise computation of GPS slant total delays and mapping factors utilizing a numerical weather model, Radio Sci., 49, 207216, https://doi.org/10.1002/2013RS005280, 2014.

Zus, F., Dick, G., Dousa, J., and Wickert, J.: Systematic errors of mapping functions which are based on the VMF1 concept, GPS Solut., 19, 277-286, https://doi.org/10.1007/s10291-014-0386-4, 2015. 